\title{
BIBLIOGRAFIA ANOTADA DE Y SOBRE ALBERTO BLEST GANA
}

\author{
POR \\ JORGE ROMAN-LAGUNAS \\ University of Arizona
}

El tema predilecto de los trabajos de mayor envergadura sobre Blest Gana ha sido la confrontación del acontecer novelesco con la situación bistórica, tanto en lo político como en lo costumbrista. El «retrato social» ha sido el tema de las cuatro tesis doctorales monográficas sobre el novelista y tópico de innumerables estudios, comentarios y referencias. Recordemos que el propio Blest Gana se definía como «novelista social» y que su contemporáneo José Victorino Lastarria señalaba el retrato de la sociedad como el aspecto de mayor mérito en su obra. Las conclusiones de estos estudios han sido: la constatación de su apego al hecho histórico, la minuciosa observación de las costumbres, la autenticidad de los retratos, su nacionalismo literario, su interés por novelar la historia del país y su visión crítica frente a las condiciones sociales de la época.

Blest Gana fue un escritor con un programa costumbrista e histórico y sus críticos han mostrado en forma más que suficiente el cumplimiento riguroso de dicho programa. Sus novelas más importantes llevaban subtítulos que fueron suprimidos por los editores después de la muerte del novelista: «novela de costumbres», «novela histórica», «novela de costumbres político-sociales», en circunstancias de que se trata de subtítulos que no sólo muestran el objetivo específico de su programa, sino además denotan la intención cíclica de su obra.

Dicho programa no alcanza sólo a la novela: se expresa análogamente en el artículo de costumbres. El conjunto de éstos todavía no ha sido objeto de estudios críticós, a pesar de que existen dos buenas compilaciones: la de José Zamudio (1947) y la de Raúl Silva Castro (1956). Creemos que estudiando estos artículos se podrán obtener interesantes conclusiones. Por ejemplo, respectó al llamado realismo moderado de Blest Gana, a su denuncia política de tono menor, a su crítica social, 
que nace contenida porque se practica desde el interior del sistema, corresponden colaboraciones periodísticas como «Las elecciones. Estudio sólo de costumbres».

Blest Gana vio la sociedad estructurada en clases y así la retrató en sus novelas. La crítica ha señalado atinadamente la escasa penetración psicológica del narrador en sus personajes. Lo que ocurre es que la intención de Blest Gana no fue de ninguna manera el estudio de la conciencia (no lo fue en toda la novela hispanoamericana del siglo XIX), sino el de las clases sociales y las costumbres. Sus personajes son representantes estereotipados de una clase social, en los cuales se observan los usos y costumbres correspondientes a cada estamento. No penetró «en el alma» porque quería observar comportamientos exteriores (costumbres) ni otorgó identidad individual a sus personajes porque los cargó con el peso de una simbología social: Martín Rivas es la clase media y Cámara es la clase baja.

Junto a la falta de penetración psicológica, se ha observado su facilidad para «crear intrigas», su "gusto por el enredo». La intriga de índole multitudinaria obedece también al propósito de retrato social: en sus novelas mayores pretendió mostrar la sociedad lo más ampliamente posible, y a ese objetivo responde la abundancia de todo tipo de personajes, los que muestran en su peripecia la estructura social encarnada.

Nosotros vemos una relación directa entre la «intriga complicada» y la «falta de penetración psicológica»: ambas responden al mismo programa literario del retrato social.

Otro aspecto en que la crítica ha mostrado interés es en el de las influencias. Dentro de este asunto, los estudios Balzac-Blest Gana constituyen legión, y hasta las más insignificantes referencias en trabajos panorámicos nunca dejan de mencionar este aspecto, anunciado ya por el propio novelista, en su difundida profesión de fe balzaciana. Balzac es el elemento catalizador de su proyecto. Leyendo a Balzac, juró ser novelista social, y su obra (sin variaciones ni evoluciones significativas) llevó a cabo rigurosamente dicho proyecto.

El lector también encontrará numerosos trabajos que discuten la ubicación de la obra de Blest Gana en el desarrollo de la novela hispanoamericana. Para algunos su novela es romántica con algunas notas realistas; para otros es «el primer realista de nuestra lengua», $y$ hay quienes llegan a relacionarlo con el Naturalismo, relación que nos parece totalmente desenfocada.

Los temas señalados y otros -estilo, influencia en la novela posterior, temática, etc.- han sido tratados ya por más de un siglo y es posible seguir el estado de las investigaciones en algunos de estos aspectos 
desde la crítica contemporánea al novelista, hasta los modernos estudios estructurales de la actualidad.

La casi totalidad de la crítica ha enfocado no más de cinco de las diecisiete novelas que Blest Gana publicó. Las obras anteriores a $L a$ aritmética en el amor se señalan como tanteos o esbozos de novela, y en ésta se ve el inicio del género en Chile y el punto de partida de la serie novelística del autor. Las otras cuatro que cuentan ya con un aparato crítico apreciable son Martín Rivas, Durante la Reconquista, El loco Estero y El ideal de un calavera, en ese orden. De las doce restantes, hay relativamente pocas reediciones disponibles y hay ciertas novelas, como Juan de Aria, que son casi totalmente desconocidas. Resulta evidente que muchos de los autores de estudios de conjunto sobre el novelista las han dejado de lado, contentándose con repetir los juicios de Silva Castro, Díaz Arrieta o Amunátegui Solar. Una revisión efectiva de estas obras - y con métodos vigentes- podría resultar del mayor provecho.

En cuanto a la bibliografía de Blest Gana, nuestro trabajo se limita a lo específicamente literario. No hemos considerado ni sus cartas (excepto las relacionadas con lo literario) ni los documentos oficiales suscritos por Blest Gana, tanto en la Intendencia de Colchagua como los que tienen que ver con sus labores diplomáticas en Francia e Inglaterra. Díaz Arrieta señala la existencia de 150 cartas inéditas y 21 publicadas, y Silva Castro transcribe algunas en su obra Alberto Blest Gana (1941). Posteriormente Sergio Fernández Larraín ha publicado un epistolario ABG-Cifuentes en el Boletín de la Academia chilena de la Historia (N. ${ }^{\circ} 72,1965$ ). De todas las cartas publicadas (no conocemos las inéditas) consignamos sólo las de interés literario. Respecto a los documentos oficiales, puede consultarse el citado libro de Silva Castro, en el cual figuran 22 documentos firmados por $A B G$ o relacionados directamente con él.

Finalmente, algunas advertencias sobre el material que presentamos:

a) La anarquía que se observa en la numeración de las ediciones de las novelas se debe casi siempre o a descuido de las editoriales o a que éstas a veces sólo consideran sus propias ediciones, sin tomar en cuenta las anteriores.

b) Algunos artículos periodísticos que consignamos no tienen la fecha completa: casi todos los recolectamos en el archivo del P. Alfonso M. Escudero y es prácticamente imposible dar con la fecha precisa.

c) Para la consulta del aporte individual de los críticos a la bibliografía de $A B G$ hemos confeccionado el «Indice onomástico».

d) Cuando no indicamos lugar de la publicación, éste es Santiago (Chile). 


\section{A) OBRAS DE ALBERTO BLEST GANA}

\section{NOVELAS *}

1. Una escena social. Novela original chilena. En El Museo (1853), Nos. 13, 14, $16,17,18,19$ y 20.

2. Una escena social. Novela original chilena. Editorial Excélsior, s/f. [posiblemente 1922]. XII + 123 pp. «Dos palabras del editor» (Luis Ignacio Silva) y prólogo de Guillermo Matta.

3. La fascinación. Una escena social. Editorial Zig-Zag, 1947. $223 \mathrm{pp}$.

4. La fascinación. Una escena social. La aritmética en el amor. Editorial ZigZag, s/f. [posiblemente 1961], 233 pp.

5. Engaños y desengaños. Novela original. En Revista de Santiago, t. I, mayo de 1855 .

6. Engaños y desengaños. Novela original. Valparaíso, Imprenta y Librería del Mercurio de S. Tornero y Cía., 1858. $190 \mathrm{pp}$.

7. La flor de la higuera: Los desposados. Engaños y desengaños. Editorial ZigZag, 1953. 256 pp.

8. Los desposados. Novela original. En Revista de Santiago, t. I, 1855 [posiblemente noviembre o diciembre].

No figura en Silva Castro-Castillo (No. 215), pero los datos que damos

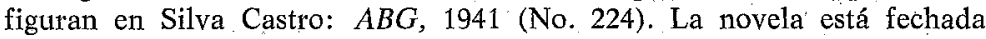
por $A B G$ en octubre.

9. La flor de la higuera. Los desposados. Engaños y desengaños. Editorial ZigZag, 1953. $265 \mathrm{pp}$.

10. El primer amor. En Revista del Pacífico, Valparaíso, t. I, 1858.

11. El primer amor. Novela original, publicada en la Revista del Pacífico. Valparaíso, Imprenta y Librería del Mercurio de S. Tornero y Cía., 1858. 94 pp.

12. El primer amor. Novela original. París-México, Librería de la viuda de Ch. Bouret, 1884. 264 pp.

13. El primer amor. Novela original. París-México, Librería de la viuda de Ch. Bouret, 1910. 264 pp.

14. El primer amor, Editorial Ziz-Zag, 1949. $165 \mathrm{pp}$.

15. El primer amor, Editorial Zig-Zag, 1964. 165 pp.

Reedición idéntica a la anterior.

16. Juan de Aria. En Revista América, Madrid, t. II, No. 20 (24-VII-1858), pp. 5-15.

17. Juan de Aria. En El Aguinaldo de El Ferrocarril, Imprenta de El Ferrocarril, No. 34, 1858. 58 pp.

18. Juan de Aria. En El Porvenir (Semana Literaria de El Porvenir), Bogotá, t. III, 1858.

No hemos logrado ver esta publicación, pero figura en el Catálogo del British Museum.

\footnotetext{
* Véanse también Nos. 190 al 193.
} 
19. Juan de Aria. Valparaíso, Imprenta y Librería del Mercurio de S. Tornero y Cía., $1859.56 \mathrm{pp}$.

20. Juan de Aria. Librería, imprenta y encuadernación de Guillermo E. Miran$\mathrm{da}, 1904.61 \mathrm{pp}$.

21. La fascinación. Novela original. En Revista del Pacífico, Valparaíso, t. I, No. 7, 1858.

22. La fascinación. Novela original. Publicada por la Revista del Pacífico. Valparaíso, Imprenta y Librería del Mercurio de S. Tornero y Cía., $1858.67 \mathrm{pp}$.

23. La fascinación. Novela original, $2 .^{2}$ ed. París, Librería de Ch. Bouret e hijo, 1875. $251 \mathrm{pp}$.

24. La fascinación. Novela original, 3.a ed., corregida por el autor. París, Librería de Ch. Bouret, 1891. 251 pp.

25. La fascinación. Buenos Aires, Biblioteca de La Argentina, vol. 21, 1908. 211 pp.

26. La fascinación. Novela original, 2. ${ }^{a}$ ed. París-México, Librería de la viuda de Ch. Bouret, 1913. 251 pp.

27. La fascinación. Novela original, 3 . $^{\mathrm{a}}$ ed., corregida por el autor. París-México, Librería de la viuda de Ch. Bouret, 1913. $251 \mathrm{pp}$.

28. La fascinación. Una escena social. Editorial Zig-Zag, 1947. 133 pp.

29. La fascinación. Una escena social. La aritmética en el amor. Editorial ZigZag, [¿1961?]. 233 pp.

30. Un drama en el campo. En La Semana, vol. I, Nos. 8-9, julio de 1859.

31. Un drama en el campo. En La Voz de Chile, Nos. 181 al 183, octubre de 1862.

32. Un drama en el campo. La venganza. Mariluán. Imprenta de La Voz de Chile, 1862. $251 \mathrm{pp}$.

33. Un drama en el campo. La venganza. Mariluán. París, A. Bouret e hijos, 1876. 294 pp.

34. Un drama en el campo. La venganza. Mariluán. Editorial Zig-Zag, 1949. $247 \mathrm{pp}$.

35. Un drama en el campo. La venganza. Mariluán. Editorial Zig-Zag, 6. ed., 1968. 243 pp.

36. La aritmética en el amor. Novela de costumbres. Obra premiada por la Universidad de Chile. Valparaíso, Imprenta y Librería del Mercurio de S. Tornero, $1860.576 \mathrm{pp}$.

37. La aritmética en el amor. Novela de costumbres, 2. ${ }^{\text {a }}$ ed., corregida por el autor. París, Librería de Bouret e hijo, 1875. 2 vols.

«La descripción completa de estos volúmenes nos es desconocida. Su existencia es indudable» (Silva Castro-Castillo). Tampoco hemos logrado verla. Figura en el National Union Catalog Pre 56.

38. La aritmética en el amor. Novela de costumbres, $3 .^{2}$ ed., corregida por el autor. París-México, Librería de la viuda de Ch. Bouret, 1897. Vol. I: 322 pp.; vol. II: $309 \mathrm{pp}$.

39. La aritmética en el amor. Novela de costumbres, 3. ${ }^{a}$ ed., corregida por el autor. París-México, Librería de la viuda de Charles Bouret, 1914. 2 vols.

40. La aritmética en el amor. Novela de costumbres. Editorial Zig-Zag, 1950. $508 \mathrm{pp}$.

41. La aritmética en el amor. En Obras selectas de ABG. Buenos Aires, El Ateneo, 1970. 3 vols. 
42. El pago de las deudas. Novela original. En Revista del Pacífico, Valparaíso, t. $4,1861$.

43. El pago de las deudas. Novela original. Valparaíso, Imprenta y Librería del Mercurio de S. Tornero, $1861.98 \mathrm{pp}$.

44. El pago de las deudas. Novela original. Nueva edición, corregida por el autor. París, Librería de A. Bouret e hijo, 1875. 288 pp.

45. El pago de las deudas. Novela original. Corregida por el autor. París, Librería de Ch. Bouret, 1884. 288 pp.

46. El pago de las deudas. Novela original. Imprenta de La Democracia, 1895. $136 \mathrm{pp}$.

47. El pago de las deudas. Novela original. Nueva edición, corregida por el autor. París-México, Librería de la viuda de Ch. Bouret, 1911. 188 pp.

48. El pago de las deudas. Imprenta Renacimiento, $1915.136 \mathrm{pp}$.

49. El pago de las deudas. Editorial Zig-Zag, 1947. $166 \mathrm{pp}$.

50. El pago de las deudas. Editorial Zig-Zag, 1949. $166 \mathrm{pp}$.

51. El pago de las deudas. Editorial Zig-Zag, 3. ed., 1968.

52. Mariluán. Crónica contemporánea. En La Voz de Chile, Nos. 186 al 200, octubre-noviembre de 1862.

53. Un drama en el campo. La venganza. Mariluán. Véase No. 32.

54. Un drama en el campo. La venganza. Mariluán. Véase No. 33.

55. Un drama en el campo. La venganza. Mariluán. Véase No. 34

56. Un drama en el campo. La venganza. Mariluán. Véase No. 35.

57. La venganza. Tradición limeña. En La Voz de Chile, Nos. 15 al 17, marzo de 1862.

58. Un drama en el campo. La venganza. Mariluán. Véase No. 32.

59. Un drama en el campo. La venganza. Mariluán. Véase No. 33.

60. Un drama en el campo. La venganza. Mariluán. Véase No. 34.

61. Un drama en el campo. La venganza. Mariluán. Véase No. 35.

62. Martín Rivas. Novela de costumbres politico-sociales. En La Voz de Chile, Nos. 47 y 109, mayo-julio de 1862.

No hemos visto esta publicación y transcribimos la descripción de Silva Castro-Castillo.

63. Martín Rivas. Novela de costumbres político-sociales. Imprenta La Voz de Chile, 1862. 197 pp.

64. Martín Rivas. Novela de costumbres politico-sociales. Buenos Aires, Imprenta del Siglo, $1869.420 \mathrm{pp}$.

65. Martín Rivas. Novela de costumbres político-sociales. Nueva edición, París, Librería de A. Bouret e hijo, 1875. Vol. I: 359 pp.; vol. II: 348 pp.

66. Martín Rivas. Novela de costumbres político-sociales. París-México, Librería de Ch. Bouret, 1884. Vol. I: 374 pp.; vol. II: 344 pp. 
67. Martín Rivas. Novela de costumbres chilenas. Oficinas de El Chileno, 1905. Vol. I: 363 pp.; vol. II: 338 pp.

El vol. II apareció con el siguiente título: La Jornada del 20 de abril de 1851 y última parte de Martín Rivas.

68. Martín Rivas. Novela de costumbres politico-sociales. París-México, Librería de la viuda de Ch. Bouret, 1910. 2 vols.

Carlos Schaible (véase No. 213) describe el primer vol.: 344 pp. Y el National Union Catalog señala la existencia de los vols. I y II, sin indicar número de páginas.

69. Martín Rivas. Novela de costumbres político-sociales. Nueva edición, ParísMéxico, Librería de la viuda de Ch. Bouret, 1924. Vol. I: 374 pp.; vol. II: $344 \mathrm{pp}$.

70. Martin Rivas. Imprenta El Mercurio (Folletines de El Mercurio), 1925. Vol. I: 167 pp.; vol. II: 163 pp.

Esta es la primera edición que suprime el subtítulo «novela de costumbres político-sociales». Sospechamos que la voluntad del autor fue mantener este subtítulo. Sigue figurando en la edición de Ch. Bouret de 1931, que es la última de esa casa editora, pero es suprimido de aquí en adelante por todas las ediciones, chilenas o extranjeras. Resulta claro que no se suprimió el subtítulo en vida de $A B G$. Semejante situación puede observarse en otras novelas de ABG. Véanse, por ejemplo, los casos de El ideal de un calavera, El loco Estero o Durante la Reconquista.

71. Martín Rivas. Novela de costumbres chilenas. Edited with Introduction, Notes and Vocabulary by G. W. Umphrey. Boston-New York, Heath and Company, 1926. XV +269 pp.

Esta edición y la de 1905 (No. 67) alteran arbitrariamente el subtítulo La presente edición es abreviada para finalidades escolares.

72. Martín Rivas. Novela de costumbres politico-sociales. Nueva edición, ParísMéxico, Librería de la viuda de Ch. Bouret, 1931. Vol. I: 374 pp.; vol. II: $374 \mathrm{pp}$.

73. Martin Rivas. Editorial Ercilla, 1936. 163 pp.

74. Martin Rivas. Editorial Zig-Zag, 1938. 314 pp.

75. Martín Rivas. Ediciones Ercilla, 1941. $4+159$ pp.

76. Martín Rivas. Editorial Zig-Zag, 3. ${ }^{\mathrm{a}}$ ed., 1944. $381 \mathrm{pp.}$

77. Martin Rivas. Editorial Orbe, $1946.358 \mathrm{pp}$.

78. Martin Rivas. Editorial Zig-Zag, 4. ${ }^{\mathrm{a}}$ ed., 1948. 381 pp.

79. Martín Rivas. Editorial Zig-Zag, 5. ${ }^{\mathrm{a}}$ ed., $1955.388 \mathrm{pp}$.

80. Martín Rivas. Editorial Zig-Zag, 6." ed., 1956. 388 pp.

81. Martín Rivas. Editorial Zig-Zag, 8. ${ }^{2}$ ed., 1961. 387 pp.

82. Martin Rivas. Buenos Aires-Santiago-Barcelona, Editorial del Nuevo Extremo, 1961. $388 \mathrm{pp}$.

Pie de imprenta: «Impreso en Barcelona por Emegé».

83. Martín Rivas. Editorial Zig-Zag, 9. ${ }^{\mathrm{a}}$ ed., 1963. 387 pp.

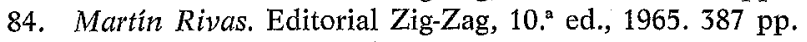

85. Martin Rivas. Editorial Pomaire, 1965. 387 pp. 
86. Martin Rivas. Editorial Zig-Zag, 11. ed., 1967. 387 pp.

87. Martín Rivas. Editorial Orbe, 1969. 337 pp.

88. Martín Rivas. Buenos Aires, Editorial Andina, 1969. 337 pp.

89. Martin Rivas. Editorial Zig-Zag, 12." ed., 1969. 387 pp.

90. Martín Rivas. En Obras Selectas de ABG. Buenos Aires, El Ateneo, 1970. 3 vols.

Martín Rivas aparece en el vol. I. La edición lleva prólogo de Hernán Díaz Arrieta (Alone).

91. Martin Rivas. Joaquín Almendros editor, 1971. 337 pp.

92. Martín Rivas. Editorial Pomaire, 1972. $388 \mathrm{pp}$.

93. Martín Rivas. Editorial Nacional Quimantú, 1. ${ }^{a}$ ed., 1973. 428 pp.

Prólogo de Jaime Concha.

94. Martín Rivas. Editorial Nacional Gabriela Mistral, 1974. 428 pp.

Prólogo de Hernán Díaz Arrieta (Alone).

95. Martín Rivas. Editorial Nacional Gabriela Mistral, 1975. 428 pp.

Prólogo de Hernán Díaz Arrieta (Alone).

96. Martín Rivas. Editorial Nascimento, 1975. Vol. I: 291 pp; vol. II: 298 pp. Prólogo (vol. I) y «Fuentes de consulta sobre $A B G »$ (vol. II) de Jorge Román-Lagunas.

97. Martin Rivas. Barcelona, Editorial Vosgos, 1977. 429 pp.

Prólogo y «Bibliografía fundamental» de Jorge Román-Lagunas.

98. El ideal de un calavera. Novela de costumbres. En La Voz de Chile, Nos. 438 y 539 , agosto-diciembre de 1863.

No hemos visto esta publicación y transcribimos la descripción de Silva Castro-Castillo.

99. El ideal de un calavera. Novela de costumbres. Imprenta La Voz de Chile, 1863.

100. El ideal de un calavera. Novela de costumbres, $2 .^{a}$ ed., corregida por el autor. París-México, Librería de A. Bouret e hijo, 1877. Vol. I: 430 pp.; vol. II: $452 \mathrm{pp}$.

101. El ideal de un calavera. Novela de costumbres. París-México, Librería de la viuda de Ch. Bouret, 3."a ed., 1893. 2 vols.

102. El ideal de un calavera. Novela de costumbres. París-México, Librería de la viuda de Ch. Bouret, 3. ${ }^{a}$ ed., 1908. Vol. I: VII +346 pp.; vol. II: $\mathrm{VI}+351 \mathrm{pp}$.

Hay una «Advertencia del autor», pp. V-VII del vol. I.

103. El ideal de un calavera. Novela de costumbres. París-México, Librería de la viuda de Ch. Bouret, 3. ${ }^{a}$ ed., 1918. Vol. I: 346 pp.; vol. II: 351 pp.

104. El ideal de un calavera. Novela de costumbres. París, Librería de la viuda de Ch. Bouret; México, Sociedad de edición y de librería franco-americana, 3. ${ }^{a}$ ed., 1925. Vol. I: 346 pp.; vol. II: $351 \mathrm{pp}$. 
105. El ideal de un calavera. Novela de costumbres. En Revista Biblioteca ZigZag, Nos. 27-28, 1931.

106. El ideal de un calavera. Editorial Zig-Zag, 1933. Vol. I: 161 pp; vol. II: $180 \mathrm{pp}$.

107. El ideal de un calavera. Editorial Zig-Zag, 1942. 462 pp.

Prólogo de Armando Bazán.

108. El ideal de un calavera. Editorial Zig-Zag, 3. ${ }^{a}$ ed., 1946. 468 pp.

Prólogo de Hernán Díaz Arrieta (Alone).

109. El ideal de un calavera. Editorial Zig-Zag, 4. ${ }^{a}$ ed., 1955. 473 pp.

110. El ideal de un calavera. Editorial Zig-Zag, 5. ${ }^{a}$ ed., 1960. 226 pp.

111. El ideal de un calavera. Editorial del Nuevo Extremo, 1961. 494 pp.

112. El ideal de un calavera. Santiago-Buenos Aires-Barcelona, Editorial del Nuevo Extremo, 1942. 495 pp.

Pie de imprenta: «Impreso en Barcelona por Emegé».

113. El ideal de un calavera. Editorial Zig-Zag, 6." ed., 1964. 226 pp.

Prólogo de Hernán Díaz Arrieta (Alone).

114. El ideal de un calavera. En Obras Selectas de ABG. Buenos Aires, El Ateneo, 1970. 3 vols.

El ideal de un calavera aparece en el vol. I. La edición lleva prólogo de Hernán Díaz Arrieta.

115. El ideal de un calavera. Barcelona, Editorial Pomaire, 1972. $494 \mathrm{pp}$.

116. La flor de la higuera. En El Independiente, 31 de marzo y 1, 2 y 5 de abril de 1864.

117. La flor de la higuera. Los desposados. Engaños y desengaños. Editorial ZigZag, 1953. 265 pp.

118. Durante la Reconquista. Novela histórica. París, Garnier Hermanos, 1897. Vol. I: 533 pp.; vol. II: 582 pp.

119. Durante la Reconquista. Novela histórica. París, Casa editorial Garnier Hermanos, s/f. Vol. I: 533 pp.; vol. II: 582 pp.

Silva Castro-Castillo suponen que esta edición es posterior a 1897. Creemos que puede ser de 1909 a 1912, porque presenta las mismas características de las ediciones de Gladys Fairfield y El loco Estero, fechadas en 1912 y 1909, respectivamente. Y las ediciones de Garnier anteriores o posteriores a dichas fechas son bien distintas.

120. Durante la Reconquista. Empresa Letras, 1933. Vol. I: 415 pp.; vol. II: $461 \mathrm{pp}$.

Prólogo de Alejandro Fuenzalida Grandón.

121. Durante la Reconquista. Editorial Zig-Zag, 1942. Vol. I: 486 pp.; vol. II: $514 \mathrm{pp}$.

Prólogo de Armando Bazán.

122. Durante la Reconquista. Editorial Zig-Zag, 2." ed., 1946. Vol. I: 486 pp.; vol. II: 514 pp.

Prólogo de Roque Esteban Scarpa. 
123. Durante la Reconquista. Editorial Zig-Zag, 3. ${ }^{2}$ ed., 1952. Vol. I: 486 pp.; vol. II: $514 \mathrm{pp}$.

Prólogo de Roque Esteban Scarpa.

124. Durante la Reconquista. Editorial Zig-Zag, 4. ${ }^{a}$ ed., 1960. 2 vols.

125. Durante la Reconquista. Editorial Zig-Zag, 5." ed., 1963. 2 vols.

126. Durante la Reconquista. Editorial Pomaire, s/f. [posiblemente 1961]. 2 vols.

127. Durante la Reconquista. En Obras Selectas de $A B G$, Buenos Aires, El Ateneo, 1970.3 vols.

128. Los trasplantados. París, Garnier Hermanos, 1904. Vol. I: 333 pp.; vol. II: $526 \mathrm{pp}$.

129. Los trasplantados. París, Garnier Hermanos, 1911. Vol. I: 333 pp; vol. II: $526 \mathrm{pp}$.

130. Los trasplantados. Empresa Letras, 1936. $675 \mathrm{pp}$.

131. Los trasplantados. Editorial Zig-Zag, 1936. Vol. I: 227 pp.; vol. II: 440 pp.

132. Los trasplantados. Editorial Zig-Zag, 1945. Vol. I: 281 pp.; vol. II: 437 pp.

[Prólogo] «ABC» por Hernán del Solar.

133. Los trasplantados. Editorial Zig-Zag, 2. ${ }^{2}$ ed., 1961. 2 vol.

134. Los trasplantados. Editorial Zig-Zag, 3. a ed., 1966. 2 vols.

135. Los trasplantados. En Obras selectas de $A B G$, Buenos Aires, El Ateneo, 1970. 3 vols.

Los trasplantados aparece en el vol. I. La edición lleva prólogo de Hernán Díaz Arrieta (Alone).

136. El loco Estero. Recuerdos de la niñez. París, Garnier Hermanos, 1909. Vol. I: 202 pp.; vol. II: 213 pp.

137. El loco Estero. Recuerdos de la niñez. Editorial Zig-Zag, 1910. 303 pp.

138. El loco Estero. Recuerdos de la niñez. Editorial Zig-Zag, 1936. 303 pp.

139. El loco Estero. Recuerdos de la niñez. Editorial Zig-Zag, 1943. 323 pp.

Prólogo de Armando Bazán.

140. El loco Estero. Buenos Aires, W. M. Jackson editores, 1945. LXII + 371 pp.

Prólogo y «Fuentes consultables» de Alfonso M. Escudero. El prologuista corrige las erratas de 1a $1 .^{a}$ ed., reproducidas hasta la edición de 1936 (No. 139).

141. El loco Estero. Buenos Aires-New York, W. M. Jackson editores, 2." ed., 1946.

Prólogo y «Fuentes consultables» de Alfonso M. Escudero.

142. El loco Estero. Recuerdos de la niñez. Editorial Zig-Zag, 3. ${ }^{2}$ ed., 1947. $322 \mathrm{pp}$.

Prólogo de Hernán Díaz Arrieta (Alone).

143. El loco Estero. Recuerdos de la niñez. Editorial Zig-Zag, 5." ed., 1956. $322 \mathrm{pp}$.

144. El loco Estero y Gladys Fairfield. Editorial Zig-Zag, 1961. 172 pp.

145. El loco Estero. Santiago-Buenos Aires-Barcelona, Editorial del Nuevo Extremo, [1961]. $285 \mathrm{pp}$.

Pie de imprenta: «Impreso en Barcelona por Emegé». 
146. El loco Estero y Gladys Fairfield. Editorial Zig-Zag, 7. ed., 1965. 172 pp. Prólogo de Hernán Díaz Arrieta (Alone).

147. El loco Estero. Editorial Orbe, 1968. 281 pp.

148. El loco Estero. En Obras Selectas de $A B G$, Buenos Aires, El Ateneo, 1970. 3 vols.

El loco Estero aparece en el vol. IIỊ. La edición lleva prólogo de Hernán Díaz Arrieta (Alone).

149. El loco Estero. Editorial Nacional Gabriela Mistral, 1973. 339 pp.

Prólogo de Hernán Díaz Arrieta (Alone).

150. El loco Estero. Editorial Nacional Gabriela Mistral, 2.a ed., 1975. 339 pp.

Prólogo de Hernán Díaz Arrieta (Alone).

151. El loco Estero. Barcelona, Editorial Vosgos, 1977. 340 pp.

Prólogo y «Bibliografía» de Jorge Román-Lagunas.

152. Gladys Fairfield. París, Casa editora de Garnier Hermanos, 1912. 180 pp.

153. Gladys Fairfield. En Revista Colección universo (Editorial Zig-Zag), No. 23 (1931), pp. 3-87.

154. Gladys Fairfield. Editorial Zig-Zag, 1940. 96 pp.

En Silva Castro-Castillo y en el National Union Catalog se lee, después del títtlo: «Revista Zceta-Zceta, No. 94». No hemos logrado ver esta edición.

155. Gladys Fairfield. Editorial Zig-Zag, 1950. 197 pp.

156. El loco Estero y Gladys Fairfield.

Véase No. 144.

157. El loco Estero y Gladys Fairfield.

Véase No. 146.

\section{TEATRO}

158. El jefe de la familia. En Correo literario, noviembre-diciembre de 1858.

159. El jefe de la familia y otras páginas. Editorial Zig-Zag, 1956.

Recopilación e introducción de Raúl Silva Castro. Véase No. 195.

\section{ARTICULOS DE COSTUMBRES}

160. «Las manías». En El Museo, No. 24 (1853), p. 375.

Firmado «Abejé». Reprod. en Costumbres y viajes (No. 194) y en El jefe de la familia y otras páginas (No. 195).

161. «Un baile en Santiago». En El Museo, No. 26 (1853), p. 407.

Firmado «Abejé». Reprod. íd. anterior. 
162. "Algunos matrimonios. Estudio de costumbres». En La Semana, No. 7 (2-VII1859), pp. 102-105.

Firmado «Nadie». Reprod. íd. No. 160.

163. «Los placeres de Santiago. Estudio de costumbres». En La Semana, No. 9 (16-VII-1859), pp. 136-138.

Firmado «Nadie». Reprod. íd. No. 160.

164. «Las baraturas». En La Semana, No. 10 (23-VII-1859), pp. 150-153.

Firmado «Nadie». Reprod. íd. No. 160.

165. «Los padres y los padrinos. Estudio de costumbres». En La Semana, No. 11 (30-VII-1859).

Firmado «Nadie». Reprod. íd. No. 160.

166. «Los banquetes patrióticos. Estudio de costumbres». En La Semana, No. 12 (6-VIII-1859), pp. 180-182.

Firmado «Nadie». Reprod. íd. No. 160.

167. «Las elecciones. Estudio sólo de costumbres». En La Semana, No. 13 (13VIII-1859), pp. 201-203.

Firmado «Nadie». Reprod. íd. No. 160.

168. «Poesía y familia. Artículo doméstico». En La Semana, No. 14 (20-VIII1859), pp. 211-213.

Firmado «Nadie». Reprod. íd. No. 160.

169. "Contrastes. Lo de antes y lo de ahora». En La Semana, No. 15 (27-VIII1859), pp. 227-229.

Firmado «Nadie». Reprod. íd. No. 160.

170. «La vida. Estudio primero: el hombre». En La Semana, No. 16 (3-IX-1859), pp. 243-245.

Firmado «Nadie». Reprod. íd. No. 160.

171. "Los novios. Segundo estudio de 'Algunos matrimonios'». En La Semana, No. 17 (10-IX-1859), pp. 262-265.

Firmado «Nadie». Es continuación del No. 162. Reprod. íd. No. 160.

172. «La vida. Estudio segundo: la mujer». En La Semana, No. 38 (24-III-1860), pp. 220-224.

Firmado «Nadie». Reprod. íd. No. 160.

173. «Santiago en Cuaresma». En La Semana, No. 41 (14-IV-1860), pp. 280-283.

Firmado «Nadie». Reprod. íd. No. 160.

174. "Conversación del sábado». Serie de doce artículos en $L a$ Voz de Chile, 12, 19 y 26 de abril; 3, 10, 17, 24 y 31 de mayo; 7, 14 y 21 de junio, y 5 de julio de 1862.

Reproducidos en El jefe de la familia y otras páginas, pp. 215-322. 
175. «Los retratos en tarjetas. Estudio de costumbres». En El Correo del domingo, 20-IV-1862.

Firmado «Nadie». Reprod. íd. No. 174.

176. «Mudanzas de domicilio. Estudio de costumbres». En La Voz de Chile, 1-IX-1862.

Firmado «Nadie». Reprod. íd. No. 174.

177. «Las vacaciones». En El Independiente, 1-III-1864.

Firmado «Solama». Reprod. id. No. 160.

178. «Percances del padrinazgo». En El Independiente, 12-III-1864.

Firmado «Solama». Reprod. íd. No. 174.

179. «Los viudos». En El Independiente, 19-III-1864.

Firmado «Solama». Reprod. íd. No. 160.

180. «Los remates». En El Independiente, 12-IV-1864.

Firmado «Solama». Reprod. íd. No. 160.

181. «Los empeños». En El Independiente, 29-IV-1864.

Firmado «Solama». Reprod. íd. No. 160.

\section{TRABAJOS SOBRE LITERATURA}

182. «Camilo Henríquez considerado como periodista». En El Araucano, No. 1.769, 1856.

183. «De los trabajos literarios en Chile». En La Semana, No. 4 (11-VI-1859), pp. 51-52.

Reprod. en El jefe de la familia y otras páginas, pp. 449-453.

184. «Al señor José Victorino Lastarria». En Revista del Pacífico, t. IV, No. 316, 24-XI-1860.

Dedica El pago de las deudas a Lastarria. Véase Leavitt: Revistas Hispanoamericanas.

185. «Literatura chilena. Algunas consideraciones sobre ella». Discurso leído en la incorporación a la Facultad de Humanidades de la Universidad de Chile, el 3 de enero de 1861. En Revista del Pacífico, t. IV (1861), pp. 418-432.

Reprod. en Anales de la Universidad de Chile, t. XVII (1861), pp. 81-93; y en Raúl Silva Castro: «BG y stu novela 'La aritmética en el amor'» (Revista Atenea. Concepción, t. 139, No. 389, julio-septiembre de 1960, pp. 37-47); y en José Promis: Testimonios y documentos de la literatura chilena (1842-1975), Editorial Nascimento (1977), pp. 108-128. Discurso de gran importancia. En él ABG presenta un diagnóstico sobre la escasez de novela nacional en Chile y plantea sus ideas sobre la misma: «Tanto la novela histórica cuanto la de costumbres y la fantástica pueden prestar eminentes servicios a las letras nacionales." Sin embargo, cree que es la novela de costumbres la que está destinada a la supremacía. También se refiere a aspectos «morales» de la novela: distingue 
entre la «licenciosa pintura de escenas sin decoro» y la pintura legítima de «ciertos extravíos humanos que no pueden dejar de figurar en obras destinadas a la descripción social».

186. «Dos cartas sobre El ideal de un calavera». En Revista Chilena, t. I (mayo de 1917), pp. 134-138.

La primera (7-I-1864) está dirigida a Benjamín Vicuña Mackenna y contiene su célebre profesión de fe balzaciana: «desde un día en que, leyendo a Balzac, hice un auto de fe en mi chimenea, condenando a las llamas las impresiones rimadas de mi adolescencia, juré ser novelista...» La segunda carta (25-I-1864) está dirigida a José Victorino Lastarria.

187. «Prefacio» a Flores incultas, por Leonor Urzúa. Imprenta Santiago, 1912.

Dato de Silva Castro ( $A B G$, No. 225): prefacio fechado en París, junio de 1911. ABG manifiesta su opinión favorable sobre la intervención de la mujer en la literatura. También se refiere al movimiento feminista de la época.

V. VIAJES

188. «Viaje a los Baños de Chillán». En La Semana, 1860. No. 35 (3 de marzo): «De Santiago a Talca», pp. 149-151; No. 36 (10 de marzo): «De Talca a los Baños», pp. 172-174; No. 37 (17 de marzo): «En los Baños», pp. 192-196.

Firmado «Nadie». Reprod. íd. No. 160.

189. De Nueva York al Niágara. Imprenta Nacional, 1867. 58 pp.

Reprod. íd. No. 160.

\section{TRADUCCIONES (DE SUS NOVELAS)}

190. Martin Rivas. Translated from the Spanish by Mrs. Charles Whitman. New York, Alfred A. Knopf; London, Chapman and Hall Ltd., 1916. 431 pp.

Sobre esta traducción pueden consultarse las reseñas consignadas en los Nos. 370, 371, 373, 394 y 426.

191. Martin Rivas. Traducida del español por E. Braganskaya y Ya. Lesyuka. Moscú, Publicaciones literarias del Estado (Goslitizdat), 1963. 416 pp.

Prefacio de Ya. Lesyuka.

192. The Madman Estero. Translated from the Spanish by Mrs. Charles Whitman. London, Chapman and Hall, 1924. 207 pp.

193. L'Ideal d'un mauvais sujet. Traduit de l'espagnol par Mme. Marie Hubbard. París, Hachette, 1885. 306 pp.

\section{COMPILACIONES}

194. Costumbres y viajes. Páginas olvidadas. Textos recogidos y ordenados, con una introducción y notas por José Zamudio Z. Editorial Difusión, 1947. $303 \mathrm{pp}$. 
[Prólogo] «Blest Gana», pp. 7-15; «Esta edición», pp. 17-20; «Páginas de costumbres» (reproduce 19 artículos de costumbres), pp. 23-249. También reprod. De Nueva York al Niágara, pp. 253-303.

195. El jefe de la familia y otras páginas. Recopilación e introducción de Raúl Silva Castro. Editorial Zig-Zag, 1956. 474 pp.

«Introducción», pp. 7-12; El jefe de la familia, pp. 13-94; «Artículos de costumbres» (reproduce 23), pp. 95-385; «Páginas literarias» (reproduce «Literatura chilena. Algunas consideraciones sobre ella»), pp. 455-471; «Viajes» (reproduce «Viaje a los Baños de Chillán» y De Nueva York al Niágara), pp. 387-447.

196. Sus mejores páginas. Selección y prólogo de Manuel Rojas. Editorial Ercilla, 1960. 347 pp.

«Biografía y estudio», pp. 9-43; «Descripción de argumentos y selección» (de 17 novelas de $A B G$ ), pp. 37-347.

197. Obras selectas. Prólogo de Hernán Díaz Arrieta (Alone). Buenos Aires, E1 Ateneo, 1970.

Vol. I: La aritmética en el amor, Martín Rivas, El ideal de un calavera; vol. II: Durante la Reconquista; vol. III: Los trasplantados, El loco Estero.

\section{B) SOBRE ALBERTO BLEST GANA}

\section{BIBLIOGRAFIAS}

198. Díaz Arrieta, Hernán (Alone): en su Don Alberto Blest Gana (Editorial Nascimento, 1940).

Obras de $\mathrm{ABG}$, divididas en a) novela $(18)$; b) periodismo (una poesía y 32 artículos); c) teatro $(1)$; d) oratoria $(1)$; e) viajes $(1)$; e) correspondencia (29 cartas publicadas y 150 inéditas).

Indicaciones bibliográficas incompletas.

199. Escudero, Alfonso M.: "Fuentes consultables", al frente de su edición de El loco Estero (Buenos Aires, Jackson, 1945).

Sobre ABG. 71 títulos, por orden alfabético de autores: incluye libros, artículos y referencias. Hay un apartado del prólogo y estas «Fuentes...».

200. Flores, Angel: en su Historia y antología del cuento y la novela en Hispanoamérica. New York, Las Américas Publishing Company, 1959.

$\mathrm{Da}$ las primeras ediciones de todas las novelas de ABG y agrega 14 referencias críticas (artículos, libros).

201. - Bibliografía de escritores hispanoamericanos. New York, Gordian Press, 1975.

Da las primeras ediciones de todas las novelas de $A B G$ y agrega 32 referencias críticas. 
202. Foster, David W.: Chilean Literature. A working Bibliography of Secondary Sources. Boston, G. K. Hall and Co., 1978.

67 títulos: «Bibliographies», 2; «Critical books and These», 26; «Critical Essays», 39.

203. Gorć, Cedomil: en su La novela chilena. Los mitos degradados. Editorial Universitaria, 1968. 2. ${ }^{\mathrm{a}}$ ed.: 1970; 3. ${ }^{\mathrm{a}}$ ed.: 1971; 4. ${ }^{\mathrm{a}}$ ed.: 1976.

De ABG: 19 títulos (entre novelas y compilaciones) y 22 ediciones y una traducción de Martín Rivas. Sobre ABG: 6 estudios de conjunto y 16 referencias específicas a Martín Rivas, la mayor parte anotados.

204. universitarias de Valparaíso, 1972.

De ABG: 17 novelas en 15 ediciones. Sobre ABG: 11 títulos.

205. Grismer, Raymond L., y Mildred B. Grismer: A New Bibliography of the Literatures of Spain and Spanish America. Minneapolis, Perine Book Co., 1942.

De ABG: 14 novelas (43 ediciones y una traducción). Sobre ABG: 11 títulos.

206. IbERo-AmeriKanischen Instituts: Schlagwortkatalog. Boston, G. K. Hall and Co., 1977. Vol. 25.

19 títulos sobre ABG.

207. Instituto dE Literatura Chilena: «Martín Rivas. Bibliografía de ediciones y referencias». En Boletín del Instituto de Literatura chilena, No. 3, octubre de 1962.

20 ediciones de Martin Rivas y 22 referencias sobre dicha novela.

208. LEAVITT, Sturgis: "Chilean Literature: a Bibliography of Literary Criticism. Biography and Literary controversy». En The Hispanic American Historical Review, vol. V, 1922.

16 títulos sobre ABG, la mayor parte anotados. Pueden consultarse, también, del mismo autor: a) Hispanoamerican Literature in the United States (1932) y el suplemento de la anterior (1935); b) Revista Hispanoamericana. Indice bibliográfico 1843-1935.

209. ReLA, Walter: Guía bibliográfica de la literatura hispanoamericana desde el siglo XIX hasta 1970. Buenos Aires, Casa Pardo, 1971.

Ocho títulos sobre ABG.

210. RoMÁN-LagunAS, Jorge: «Fuentes de consulta sobre Alberto Blest Gana», en su edición de Martín Rivas, Editorial Nascimento, 1975.

244 títulos sobre $\mathrm{ABG}$, por orden alfabético de autores, parcialmente anotados.

211. — : «Bibliografía fundamental», en su edición de Martín Rivas, Barcelona, Editorial Vosgos, 1977.

Diez títulos sobre Martin Rivas, anotados.

212. — : «Bibliografía», en stı edición de El loco Estero, Barcelona, Editorial Vosgos, 1977.

Nueve títtlos sobre ABG, anotados. 
213. Schatble, Carlos: «Algunas adiciones a la bibliografía de don Alberto Blest Gana». En El bibliófilo chileno, No. 7 (agosto de 1951), pp. 84-85.

Aporta datos sobre algunas ediciones raras de novelas de ABG.

214. SILVA, Luis Ignacio: La novela en Chile. Imprenta Barcelona, 1910, pp. 34132.

Consigna 12 novelas de $\mathrm{ABG}$ en 27 ediciones. Reproduce artículos de Arteaga Alemparte, Lastarria y Amunátegui, Barros Arana, Díaz Garcés y Mackenna Subercaseaux.

215. Silya Castro, Raúl, y Castillo, Homero: "Las novelas de don Alberto Blest Gana», Revista Hispánica Moderna, vol. 23, Nos. 3-4 (julio-octubre de 1957), pp. 292-304. Reprod. en Historia bibliográfica de la novela chilena (México, Ediciones de Andrea), 1961.

Este excelente trabajo consigna gran parte de las ediciones de novelas de ABG hasta 1957. Por nuestra parte, hemos logrado agregar unos doce títulos anteriores a 1957 y hemos tratado de completar hasta 1977.

216. Silva Castro, Raúl: «Bibliografía de Alberto Blest Gana» y «Principales fuentes consultables», en su Alberto Blest Gana (Editorial Nascimento, 1941), pp. 593-632.

61 ediciones de las novelas, ordenadas por año (1851-1936), 22 documentos, 7 colaboraciones en periódicos y 7 misceláneas. Sobre ABG: 84 títulos, por orden alfabético de autores.

217. Torres-Rroseco, Arturo, y Silva Castro, Raúl: Ensayo de bibliografía de la literatura chilena. Cambridge (Massachusetts), Harvard University Press, 1935.

14 obras de $\mathrm{ABG}$ en 36 ediciones y 2 traducciones.

218. Topete, J. Manuel: A working Bibliography of Latin American Literature. St. Augustine (Florida), 1952. Reprod. por University Microfilms, Ann Arbor (Michigan), 1969.

12 novelas de ABG y 3 referencias críticas.

219. Valenzuela, Víctor M.: "Selected Critical Studies on Blest Gana", en sut Chilean Society as seen through the novelistic world of Alberto Blest Gana. (Véase No. 227.)

20 títulos.

\section{LIBROS, TESIS, MEMORIAS DE GRADO}

220. Díaz Arrieta, Hernán (Alone): Don Alberto Blest Gana. Editorial Nascimento, 1940. $338 \mathrm{pp}$.

«Biografía» (pp. 9-111), «Obra» (pp. 115-247) y «Bibliografía» (pp. 323. 329). Estudia la influencia de Balzac. Analiza cada una de las novelas de ABG (método impresionista), buscando la caracterización psicológica de los personajes. Muchas de sus observaciones, aunque poco sistemá. 
ticas, resultan brillantes, $\mathrm{y}$ han sido elaboradas por muchos estudios posteriores. Esta obra compartió el premio del Certamen Blest Gana de la Universidad de Chile con otra, homónima, de Silva Castro (véase No. 224). Los análisis de Silva Castro resultan débiles frente a las agudas observaciones y hallazgos de Alone. Este, sin embargo, no aporta la minuciosa y documentada información de aquél. Ambas obras son indispensables y se complementan.

221. Hunneus, Roberto: Don Alberto Blest Gana y la novela histórica. París, Editorial Garnier, 1897. VII + 79 pp.

«A discussion of historical novels in general, followed by an analysis of Durante la Reconquista, with illustrative selections» (Leavitt: Chilean Literature...). La obra resulta interesante como testimonio contemporáneo a la novela, pero está superada por estudios posteriores.

222. Miller, Edmund Davison: La sociedad chilena coetánea como se ve a través de las principales novelas de Alberto Blest Gana. México, Universidad Nacional Autónoma, 1949. 2.a ed., 1955.

No hemos logrado examinar esta obra.

223. Poblete Varas, Hernán: Genio y figura de Alberto Blest Gana. Buenos Aires, Editorial Universitaria de Buenos Aires, 1968. 255 pp.

Situación histórica, biografía y reflejo del acontecer histórico en las novelas de $A B G$, divididas en las que se refieren al período $1830-1853$ y al período 1853-1860. Estudia especialmente La aritmética en el amor, Martin Rivas, El ideal de un calavera y Durante la Reconquista. El capítulo VII está dedicado a la labor diplomática de ABG.

Sobre la obra, véase el artículo de Silva Castro «Blest Gana en el ambiente de su época» (No. 467).

224. Silva Castro, Raúl: Alberto Blest Gana (1830-1920). Estudio biográfico y crítico. Imprenta Universitaria, 1941. XX +652 pp. 2: edición refundida, Editorial Zig-Zag, 1955. 352 pp.

Estudia la biografía en «Libro preliminar», «Libro primero» y «Libro segundo» (pp. 4-332). De las anteriores, las últimas 100 páginas son «Notas explicativas y documentales». En los libros «Tercero» y "Cuarto» examina cada obra de ABG (pp. 335-590): si bien el análisis no se caracteriza por una metodología ceñida (aunque podemos clasificarlo como temático e histórico) ni muestra consistencia teórica, la erudita acumulación de datos resulta una fuente imprescindible - la mejor- para el estudio de la obra de ABG. El «Libro quinto» es la bibliografía (pp. 593-639).

La segunda edición refundida disminuye el texto y suprime gran parte de la documentación. Dada la índole erudita de esta obra, resulta mucho más útil la edición original que esta refundición, de la cual hasta se suprimió la bibliografía de $A B G$, que era uno de sus aspectos más importantes.

A casi cuarenta años de su primera edición, esta obra monumental sigue siendo la más importante sobre $\mathrm{ABG}$. Debemos señalar que además de ésta, Silva Castro publicó numerosos artículos sobre el novelista. El 
conjunto de sus trabajos lo transforman en la primera e indiscutida autoridad en ABG. Hernán Díaz Arrieta (Alone) lo reconoce con estas palabras: «Con su ciencia, su paciencia y su conciencia ejemplares, el gran crítico alzó al gran novelista un monumento de erudición e inteligencia comprensiva» (véase No, 411).

\section{TESIS DOCTORALES}

225. BARRET, Ivonne G.: «La realidad histórica chilena y su adaptación en cuatro novelas de Alberto Blest Gana». Florida State University, 1969. 226 pp.

Estudia Durante la Reconquista, El ideal de un calavera, El loco Estero y Martín Rivas. Analiza el apego de dichas novelas al dato histórico y el realismo en la presentación de los caracteres. Es un trabajo de orientación histórica, que desde esta perspectiva hace una clasificación de los caracteres en: a) históricamente auténticos; b) semihistóricos; c) históricos usados como «background»; d) puramente ficticios, y e) masivos, que simbolizan una clase social.

226. Phillips, Walter T.: «Chilean Customs in Blest Gana's novels». University of Southern California, 1943.

Estudia las costumbres chilenas referidas en las novelas de ABG (período 1814-1860) y confronta las observaciones del novelista con los documentos de la época para verificar su exactitud. Su conclusión es confirmar «a high degree of accuracy in Blest Gana's pictures of the customs of Chile».

227. Valenzuela, Víctor M.: Chilean Society as seen through the Novelistic World of Alberto Blest Gana. New York, Columbia University, 1965. Editada por Talleres Arancibia Hnos., 1971. 157 pp.

Examina la naturaleza cíclica de la prodtucción de ABG, estudiando sus novelas de acuerdo a los períodos históricos a que se refieren: a) Reconquista; b) República; c) Período de desarrollo cultural, social y económico. Concluye que $A B G$ es «the first to interpret in an artistic and cyclic manner the Society of his time».

228. Willson, William Charles: «The Historical Elements in the Novels of Alberto Blest Gana». University of Washington, 1928.

Señala que el interés histórico se manifiesta en cuatro novelas. Con poca importancia en El loco Estero y en El ideal de un calavera; observa una presencia mayor de la historia en Martín Rivas y califica Durante la Reconquista como "a historical novel in every sense of the word». Dedica el grueso de la tesis a esta última novela (pp. 4-181).

\section{Tesis (Master of Arts)}

229. Dunn, K. L.: «An Analysis of the Works of Alberto Blest Gana. With an Appendix Showing the Influence of Balzac». University of California (Berkeley), 1922. 
230. Heinzman, M. B.: «La mujer chilena en las novelas de Alberto Blest Gana». University of California, 1946.

231. LOGAN, M. E.: "The Works of Alberto Blest Gana». University of Illinois, 1926.

232. Mcknigt H, T. M.: «The Life and Works of Alberto Blest Gana». University of North Carolina, 1924.

233. RaYmond, Ethel G.: «The Historical Basis for Alberto Blest Gana's novel Durante la Reconquista». University of Washington, 1930.

De esta tesis hay una traducción (al parecer inédita), que cita Hernán Díaz Arrieta (Alone) en su obra sobre ABG (No. 220).

234. White h ouse, J. E.: «Alberto Blest Gana, Chilean Novelist». Columbia University, 1926.

Memorias de Grado (Profesor de Estado, en la especialidad de Castellano)

235. Aguayo Dolmetsch, Lidia: «Alberto Blest Gana y Eduardo Acevedo Díaz (uruguayo), novelistas de América». Universidad de Chile, 1948.

236. Bull Figueroa, Ernestina: «Blest Gana y sus novelas». Universidad de Chile, 1929.

237. Fuentes Rodríguez, María Teresa: «Don Alberto Blest Gana y su producción intelectual». Universidad de Chile, 1923.

238. GonZÁlez GuZMán, Adriana: «Estudio psicológico de las características de los personajes de las obras de Alberto Blest Gana». Universidad de Chile, 1929 .

239. Neves, Eugenia: «El loco Estero, de Alberto Blest Gana: análisis estructural». Universidad de Chile, 1963.

240. Núñez, Fresia: «Don Alberto Blest Gana. Breve estudio sobre sus obras». Universidad de Chile, 1921.

241. Ortiz Morales, Berta: «Evolución moral, material y espiritual en las novelas de Blest Gana y Orrego Luco». Universidad de Chile, 1935.

242. PÉrez, Margot: «Alberto Blest Gana». Universidad de Chile, 1926.

243. Salgado Vera, Rosa: «El ideal de un calavera, de Alberto Blest Gana. Motivos y personajes». Universidad de Chile, 1966.

244. Santandreu, Cora: «Blest Gana y la mujer». Universidad de Chile, 1949.

245. SiLvester Briso, Inés: «Breve comentario sobre las novelas de Alberto Blest Gana». Universidad de Chile, 1923.

246. Verdugo DE Navarro, Esperanza: «Breve estudio sobre don Alberto Blest Gana». Universidad de Chile, 1925.

\section{ENSAYOS CRITICOS}

247. Amunátegui, Miguel Luis, y Lastarria, José Victorino: «Novela de don Alberto Blest Gana titulada La aritmética en el amor, a la cual la Facultad de Humanidades, en sesión del 6 del corriente, adjudicó el premio de la lei. Informe de la comisión encargada de juzgar éste y demás trabajos presentados al certamen de la expresada Facultad en el presente año». Anales de la Universidad de Chile, t. XVII (1860), pp. 999-1006. Reprod. en Obras 
completas de José V. Lastarria, vol. XI, pp. 67-79, y en Luis Ignacio Silva: La novela en Chile, pp. 45-56.

«El gran mérito de esta composición es el ser completamente chilena», decían los autores del informe. Este fue el primer espaldarazo al novelista, hasta el momento balbuceante, incipiente.

248. Amunấtegui Solar, Domingo: Bosquejo histórico de la literatura chilena. Imprenta Universitaria (1915), pp. 519-568.

Es un minucioso comentario sobre el acontecer de la mayor parte de las novelas de ABG. Puede consultarse la reseña de Hernán Díaz Arrieta (Alone) en Pacífico Magazine, t. II (1920), p. 309.

249. _-_-: Las letras chilenas. Editorial Balcells y Co. (1925), pp. 169-180. 2." ed., Editorial Nascimento, 1934.

Esta obra es un compendio de la anterior (No. 248).

250. ARAYA, Guillermo: «E1 amor y la revolución en Martín Rivas». Bulletin Hispanique, t. 77, Nos. 1-2 (1975), pp. 5-33.

Interesante y novedoso paralelo con Les misérables, de V. Hugo, en cuanto a la definición de las capas sociales.

Muestra cómo la actuación política de Martín Rivas y Rafael San Luis está motivada por evasión a sus propios problemas personales, aunque sin referirse al aspecto romántico que esta evasión podría conllevar.

Destaca la total ausencia del pueblo en las convulsiones sociales, y su pasividad.

251. Arteaga Alemparte, Justo: «Cuatro novelas de Alberto Blest Gana». La Semana, No. 14 (20-VIII-1859), pp. 209-211. Reprod. en Luis Ignacio Silva: La novela en Chile, pp. 36-45.

Se refiere a Juan de Aria, El primer amor, Engaños y desengaños y $L a$ fascinación. Silva Castro le da gran importancia a este artículo, señalando que de él arranca la atribución de la paternidad de la novela chilena a ABG. El aserto no sería nada original a no ser por la fecha tan temprana del trabajo de Arteaga.

252. Astorouiza, Eliodoro: «Don Alberto Blest Gana». Revista chilena, t. X, No. 35 (agosto de 1920), pp. 345-370. Reprod. en El Mercurio, 11-XI-1920 («Nacimiento de la novela chilena»), y en Revista Atenea, No. 389 (julioseptiembre de 1960), pp. 5-26.

Señala que las primeras novelas de $\mathrm{ABG}$ imitan los peores defectos de Balzac. Concede importancia a La aritmética en el amor: en su publicación ve el nacimiento de la novela chilena. Agudo análisis de Martín Rivas y Durante la Reconquista. Como juicio de conjunto expresa que «por su extraordinaria claridad para ver el aspecto externo de los actos y de los hombres es un excelente costumbrista», pero que «carece de penetración psicológica».

253. Barros Arana, Diego (Firmado «X»): «Martín Rivas, novela de costumbres político-sociales, por don Alberto Blest Gana». El Correo del Domingo, No. 18 (17-VIII-1862), p. 174. Reprod. en Luis Ignacio Silva: La novela en 
Chile, pp. 59-69, y en Boletín del Instituto de Literatura Chilena, No. 3 (octubre de 1962), pp. 2-3.

Es el punto de partida de los estudios sobre Martín Rivas. Decía Barros Arana: «Esto es lo que ha hecho el señor Blest Gana: ha estudiado la sociedad chilena bajo ciertas fases y la ha retratado con bastante fidelidad.» Esta importante observación de Barros Arana mantiene su vigencia aun después de revisar los estudios actuales sobre la novela.

254. - (Firmado «D. B. A.»): «Durante la Reconquista, novela histórica, por don Alberto Blest Gana». Anales de la Universidad de Chile, t. XCVII (1897), pp. 5-10. Reprod. en Luis Ignacio Silva: La novela chilena, pp. 74-84.

«Esa intriga complicada, suficiente para dos novelas, a lo menos está expuesta y desarrollada con verdadero arte, despierta y mantiene el interés y demuestra un gran poder de observación de las pasiones y de los caracteres humanos, que es la primera dote de los grandes novelistas.» Muchos críticos disienten en cuanto al segundo aspecto (pasiones y caracteres).

255. Barros Grez, Daniel: «Martín Rivas». La Voz de Chile, 9-VIII-1862.

Dice Goić que «lleva la simpatía del compañero de generación por el asunto nacional, la función social y la edificación moral de la novela» (La novela chilena).

256. Billone, Vicente Atilio: «En los comienzos del realismo americano. Las novelas de la segunda época de Alberto Blest Ganas. Humanitas, San Miguel de Tucumán (Argentina), t. XVII, No. 23 (1972), pp. 33-67.

257. CAmurati, Mireya: «Blest Gana, Lukács y la novela histórica». Cuadernos Americanos, t. 197, No. 6 (noviembre-diciembre de 1974), pp. 88-99.

Expone algunas reflexiones teóricas de Lukács y de Amado Alonso. Sostiene que Durante la Reconquista satisface (aunque con ciertas reservas) el requisito propuesto por Lukács en cuanto a que las acciones y personajes se presenten como resultante de la necesidad histórica; y el requisito de la verosimilitud poética autónoma (A. Alonso).

258. Clenc, Teresa: «Itinerario de la literatura criollista de Chile de Blest Gana a Luis Durand». Memoria de grado, Universidad de Chile, 1949.

259. Concha, Jaime: "Martín Rivas o la formación del burgués». Revista chilena de literatura, Nos. 5-6 (1972), pp. 9-35. Reprod. en Casa de las Américas, No. 89 (1975), pp. 4-18.

Estudia la personalidad de Martín Rivas, oponiéndose a la tradicional calificación de "héroe de la clase media». Ve en él a un «personaje que cumple con todas las perfecciones del burgués, menos con una: la del capital y la propiedad privada». Señala que no hay diferencia ni oposición entre Dámaso Encina y Martín, repitiendo éste la peripecia de aquél, y se refiere al matrimonio Martín-Leonor como a un «incesto económico», puesto que «ambos son hijos de la misma asociación capitalista». Es un agudo enfoque de tipo marxista. 
260. Crowley, Cornelius: «Costumbrism in Chilean Literary Prose of the 19th Century». Tesis doctoral, University of California (Berkeley), 1944.

Señala a Blest Gana como un escritor predominantemente costumbrista, que en su serie de novelas «covered almost every phase of the life of the nation». Estudia las novelas más notables desde este punto de vista: Martín Rivas, Durante la Reconquista, El loco Estero, El ideal de un calavera y Los trasplantados.

261. Cruz, Pedro Nolasco: «Don Alberto Blest Gana». La Unión (Valparaíso), 27 y 28-VII-1908. Reprod. en Estudios sobre literatura chilena, vol. II. Editorial Nascimento (1940), pp. 81-95.

Se refiere al Naturalismo [ $i$ ?] en las novelas de ABG.

262. Cuadra, Fernando: «Alberto Blest Gana y el desarrollo del teatro chileno». Revista Apuntes (Escuela de Artes de la Comunicación, Universidad Católica de Chile), No. 78 (diciembre de 1973), pp. 3-9.

263. Durand, Luis: «Las mujeres en las novelas de Blest Gana». En Alma y cuerpo de Chile. Editorial Nascimento (1947), pp. 179-206.

Se refiere a Inés Arboleda (El ideal de un calavera); a Violante, Trinidad y Luisa (Durante la Reconquista), y a Leonor Encinas (Martín Rivas), señalando que esta última es el mejor carácter femenino creado por $A B G$.

264. EDwards, Alberto: «Una excursión por Santiago antiguo. El Martín Rivas de Blest Gana y la sociedad chilena de 1850». Pacífico Magazine, t. II, No. 38 (febrero de 1916), pp. 115-128.

265. FAHRENKAMP, Billie Mae: «The European Background of Certain Spanish American Novels». Tesis (Master of Arts), University of Texas (Austin), 1946.

Estudia Los trasplantados.

266. Fraysse, Maurice: «Alberto Blest Gana et Balzac». Cahiers du Monde Hispanique et Luso-Brésilien (Caravelle), No. 20 (1973), pp. 117-134.

Estudia la influencia de Balzac en ABG en cuatro aspectos: la intención cíclica, la incorporación de la historia en la trama novelesca, el método de observación y análisis, y ciertos aspectos del estilo. Pero aclara que «l'adhésion à l'esthétique réaliste ne signifie pas pour ABG une soumission aveugle aux principes de la philosophie balzacienne». A pesar de que el asunto Balzac-ABG es un lugar común de la crítica, en este trabajo se prueba documentalmente lo que muchos otros han señalado al pasar. Fraysse ve la verdadera influencia de Balzac en las novelas de la segunda época: $1860-1909$.

267. - «La campagne chilienne et le 'huaso' dans les romans de Blest Gana». Cahiers du Monde Hispanique et Luso-Brésilien, No. 28 (1977), pp. 91-103.

Aunque la visión de Blest Gana es limitada e incompleta, señala su obra como un antecedente de la generación criollista posterior (Latorre, Maluenda, Durand). Observa que el "huaso» de ABG es impasible y que su inquilino es mudo: son los que pasarán a ser el proletario consciente de la generación de 1938. 
268. Fuenzalida Grandón, Alejandro: «Algo acerca de Blest Gana y su arte de novelar». Discurso de incorporación en la Facultad de Filosofía, Humanidades y Bellas Letras de la Universidad de Chile. Imprenta Universitaria. 1921. 2. ${ }^{2}$ ed., tirada aparte de los Anales de la Universidad de Chile, 1923. Reproducido (parcialmente) como prólogo a Durante la Reconquista (Empresa Letras, 1943).

269. Gorć, Cedomil: [«Análisis de Martín Rivas»] en La novela chilena. Los mitos degradados. Editorial Universitaria, 2. ${ }^{a}$ ed. (1970), pp. 33-39.

Después de un severo diagnóstico acerca de los estudios sobre esta novela, analiza, entre otros aspectos, la estructura del narrador y «su actitud crítica y acerbamente satírica».

270. Guerrero, Leoncio: «Alberto Blest Gana y su época». Revista Atenea, t. 146, No. 396 (abril-junio de 1962), pp. 103-114.

Se refiere a los distintos «tipos» o personajes de Martín Rivas, señalando al protagonista como símbolo de la clase media. Destaca el interés de $A B G$ en el ambiente chileno, en una época «extranjerizante».

271. Holton, James Stafford: «The Evolution of Attitudes Toward the Social Classes in the Chilean Novel». Tesis doctoral, University of California (Berkeley), 1958.

La tesis se refiere al siglo $\mathrm{xx}$, pero dedica la segunda parte del capítulo I a $A B G$, observando que retrata a las clases media y alta. En los capítulos siguientes estudia cómo la novela chilena posterior va centrando su interés en las clases media y baja.

272. Latcham, Ricardo: "Blest Gana y París». El Diario Ilustrado, 31-VII-1955. Reprod. en su Crónica de varia lección (Antología por Alfonso Calderón y Pedro Lastra), Editorial Zig-Zag, 1956; y en Raúl Silva Castro (editor): La literatura crítica de Chile, Editorial Andrés Bello, 1969.

Estudia la ambientación parisiense de Engaños y desengaños, Los desposados y La fascinación y «el extenso friso parisiense de Los trasplantados»: señala el aire balzaciano de sus visiones. Interesantes observaciones sobre el realismo de «tono menor» de $A B G$, atribuido a su moderación temperamental. También aporta datos sobre la personalidad del novelista.

273. - : «Blest Gana y la novela realista». Anales de la Universidad de Chile, No. 112 (1958), pp. 30-46. Reprod. como apartado, Ediciones AUCH (serie roja, No. 20, [1959]); y en Crónica de varia lección (véase No. 272), pp. 286-310.

Estudia la influencia de Balzac (en cuanto al amor y al dinero), Scott y Dickens. Insiste en la idea del realismo moderado («no vio las contradicciones del medio») especialmente en La aritmética en el amor, Martín Rivas y El ideal de un calavera. En cuanto a Los trasplantados, la relaciona con obras de José Tomás de Cuéllar, Alberto del Solar, Joaquín Edwards Bello, Martín Aldao y Binet-Valmer. 
274. Latorre, Mariano: «El pueblo en las novelas de Blest Gana». Revista Atenea, No. 100 (agosto de 1933), pp. 180-197.

En toda la obra novelística de ABG el pueblo está en colectividad, excepto en Durante la Reconquista, donde cuenta la presencia de ocho tipos populares. El personaje Cámara es la creación más completa del «roto» que hay en la literatura chilena.

275. Loyola, Hernán: "Don Guillermo y Martín Rivas: visión paralela». En Cedomil Goić y otros: La novela hispanoamericana: descubrimiento e invención de América. Valparaíso, Ediciones universitarias de Valparaíso (1973), pp. 55-70.

Compara el «romanticismo social» de Lastarria con el de ABG. Al primero lo califica de "gesticulante y esquemático» y al segundo como «realista y de mayor complejidad».

276. Melfi, Domingo: «Blest Gana y la sociedad chilena». Revista Atenea, No. 100 (agosto de 1933). Reprod. en Estudios de literatura chilena. Primera serie, Editorial Nascimento (1938), pp. 23-47.

Estudia la obra de ABG como expresión de la sociedad. Su tesis es que el género novela sigue como consecuencia a la formación de un pueblo y señala a $\mathrm{ABG}$ como el novelista que ve la sociedad chilena ya estructurada.

277. —-: «Una sombra en Blest Gana». En El viaje literario. Editorial Nascimento (1945), pp. 46-51.

Explica el aspecto «cursi» del estilo de ABG como reflejo del ambiente en que el novelista vivió.

278. _- «El héroe de la clase media en la novela chilena». Revista Atenea, No. 61 (1930), pp. 65-69.

«... por primera vez un escritor chileno, un novelista, hacía la apología del hombre humilde y lo llevaba, después de sucesivos obstáculos y luchas con el medio, al logro de sus ambiciones.» (Se refiere a Martín Rivas.) Relaciona este asunto con el desarrollo histórico-social del país y agrega que Martín Rivas dio origen a «una legión de novelistas» que plantearon conflictos semejantes. Sólo menciona seis novelas de esa «legión», entre ellas Un idilio nuevo, de Luis Orrego Luco.

279. Merino Reyes, Luis: «Alberto Blest Gana». En Perfil humano de la literatura chilena. Editorial Orbe (1967), pp. 43-51.

Trabajo principalmente biográfico.

280. Miranda Lazcano, Rebeca: «Cuatro novelistas chilenos y sus principales personajes femeninos: Alberto Blest Gana, Vicente Grez, Luis Orrego Luco y Moisés Vargas». Memoria de grado, Universidad de Chile, 1950.

281. Montaner Bello, Ricardo: «La labor diplomática de don Alberto Blest Gana». Revista chilena, No. 42 (julio de 1921), pp. 225-234.

282. Morand, Carlos: Visión de Santiago en la novela chilena. Tesis doctoral, 
The University of Iowa, 1975. Editada por Ediciones Aconcaguta (1977). $196 \mathrm{pp}$.

Estudia Martín Rivas como «novela urbana de retrato», según la clasificación de B. H. Gelfant. Entre otros aspectos, examina los recursos del narrador para la presentación del escenario urbano: nombres de calles, caracterización del lugar, dato histórico y «cuadro» costumbrista.

283. Phillips, Walter Thomas: «Chilean Customs in the Novels of Alberto Blest Gana». Hispania, vol. 24, No. 4 (diciembre de 1943), pp. 397-406.

Es una síntesis de su tesis doctoral (véase No. 226).

284. Pool, Alice M.: «La influencia francesa en tres novelistas iberoamericanos del siglo XIX». Tesis doctoral, Universidad Nacional Autónoma (México), 1950.

Se refiere a ABG (capítulo II), Altamirano e Isaacs. Estudia la influencia de Balzac en ABG, comparando los cuadros de París y provincias del novelista francés con los análogos del chileno. La relación con Balzac la ve en el costumbrismo, el carácter de un personaje dominado por una pasión, en la importancia del dinero, en la familia como base de la trama y en el rasgo romántico del realismo.

También señala (tangencialmente) la influencia de Stendhal.

285. Rodríguez MendozA, Emilio: «Blest Gana. Sus novelas y sus tipos». El Mercurio, 24, 26 y 29-X-1911.

286. Rossel, Milton: «En compañía de Martín Rivas». El Mercurio, 25-IX-1962. Reproducido en Revista Atenea, No. 396 (1962), pp. 93-102 («Pasado y presente de Martin Rivas»).

Señala el contraste socioeconómico entre los personajes como leit-motiv no sólo de esta novela, sino de otras, como El loco Estero y El ideal de un calavera. Propone una tipología de los personajes, como reflejos de la sociedad chilena. Ve a Martín como encarnación de los ideales políticos del autor y se pregunta si no puede calificarse esta novela como «literatura comprometida» (con la doctrina liberal).

287. Salmon, Russel: «The roto in Chilean Prose Fiction». Tesis doctoral, Columbia University, 1969.

Estudia el tema desde la generación de 1841 hasta los contemporáneos. En el primer período estudia a José Joaquín Vallejo, Daniel Riquelme y Blest Gana. Especialmente Cámara, personaje de Durante la Reconquista.

288. - : «Alberto Blest Gana como retratista del roto». Cahiers du Monde Hispanique et Luso-Brésilien, No. 20 (1973), pp. 135-148.

Estudia al «roto» en las figuras de ño Cámara (Durante la Reconquista) y Chanfaina (El loco Estero). Al primero lo destaca como una idealización estilizada y concluye que es «una excelente visión de cómo las clases superiores del siglo XIX concebían la vida de los pobres. En cuanto al segundo, se pregunta si se trata de la visión del estado de bestialidad del pueblo o de un símbolo romántico del mismo. 
289. SchaDE, George D.: «Notas sobre Martín Rivas: evaluación y vigencia». En La literatura iberoamericana del siglo XIX (Memoria al XV Congreso Internacional de Literatura Iberoamericana). Tucson, University of Arizona, 1971 (Renato Rosaldo y Robert R. Anderson, editores), pp. 149-154.

290. Segura, Carlos: «Tipos chilenos en la novela y en el cuento nacional». Anales de la Universidad de Chile, Nos. 25-26 (1937), pp. 65-85.

Véase especialmente «Ño Cámara, símbolo del pueblo chileno», pp. 71-74.

291. Silva Castro, Raúl: «Un centenario olvidado: Blest Gana». El Mercurio, [posiblemente] 1930.

292. - :Santiago a través de algunas novelas de Blest Gana». El Mercurio, 12-II-1941.

293. _- «Alberto Blest Gana». En Creadores chilenos de personajes novelescos. Editorial Biblioteca de Alta Cultura, 1952. Reprod. en Panorama de la novela chilena (1843-1954), México, Fondo de Cultura Económica, 1955; y en Cuadernos Hispanoamericanos (Madrid), vol. 31, No. 90 (junio de 1957), pp. 324-346 («La obra novelística del chileno Alberto Blest Gana»); y en Historia critica de la novela chilena (1843-1956), Madrid, Ediciones de Cultura Hispánica, 1960; y en Panorama literario de Chile, Editorial Universitaria, 1961.

Este trabajo, reproducido tantas veces, es una buena síntesis del pensamiento de Silva Castro sobre la obra de ABG.

294. - : «Martín Rivas redivivo». El Mercurio, 7-V-1954.

295. — : «Blest Gana y su novela La aritmética en el amor». Revista Atenea, vol. 234, No. 389 (julio-septiembre de 1960), pp. 27-47.

Se refiere al certamen de novela en que Blest Gana ganó el premio con esta novela. También reproduce el informe de Amunátegui y Lastarria (véase No. 247) y el discurso de incorporación de ABG a la Facultad de Humanidades (No. 185).

296. - - «Ante el centenario de Martín Rivaș». El Mercurio, 25-V-1962.

297. - : «Martín Rivas al cabo de cien años». El Mercurio, 30-V-1962.

298. - : "Centenario de Martín Rivas», Revista Iberoamericana (México), vol. 29, No. 55 (enero-junio de 1963), pp. 139-146. Reprod. en Estampas y ensayos, México, Fondo de Cultura Económica (1968), pp. 9-16.

Este trabajo es una versión aumentada de «Ante el centenario...» (No. 296).

299. __ : «Blest Gana en el ambiente de su época». El Mercurio, 28-VII-1968. Se refiere al libro de Poblete Varas Genio y figura de $A B G$ (No. 223), aunque el artículo rebasa el propósito de reseñar dicho libro.

300. - - «Blest Gana y su novela Durante la Reconquista». Revista chilena de Historia y Geografía, No. 84, 1934. Reprod. como tirada aparte, Imprenta Universitaria, 1934.

Sobre este trabajo pueden consultarse las reseñas de Omer Emeth (El Mercurio, 11-X-1934) y de C. Winter (Books Abroad, vol. X, 1936).

301. Vicuña Mackenna, Benjamín: «La novela en Chile: El ideal de un calavera». El Mercurio (Valparaíso), 4-I-1864. Reprod. en Silva Castro: $A B G$, edición de 1941 (véase No. 224). 
302. Von Dem Bussche, Gastón: «Vigencia de Martín Rivas». En Diez conferencias. Concepción, Talleres de la Imprenta de la Universidad (1963), pp. 53-97.

303. Wilson, William E.: «Blest Gana's debt to Barros Arana». Hispanic American Historical Review, vol. 19, No. 1 (febrero de 1939), pp. 102-105.

\section{PROLOGOS}

304. BAZÁN, Armando: a Durante la Reconquista. Editorial Zig-Zag, 1942.

305. - : a El ideal de un calavera. Editorial Zig-Zag, 1942.

306. ConchA, Jaime: a Martín Rivas. Editorial Nacional Quimantú, 1976, pp. 7-14.

307. DEL SolAR, Hernán: a Los trasplantados. Editorial Zig-Zag, 1945.

308. Díaz Arrieta, Hernán (Alone): a El ideal de un calavera. Editorial ZigZag, 1946. También en «6." ed.», 1965.

309. - a Martín Rivas. Editorial Nacional Gabriela Mistral, 1974.

Este prólogo es una reproducción de las pp. 179-185 de su Historia personal de la literatura chilena (véase No. 335).

310. - : a Obras selectas de $A B G$. Buenos Aires, El Ateneo, 1970.

311. Escudero, Alfonso M.: a El loco Estero. Buenos Aires, Editorial Jackson, 1945, pp. I-LI.

Este enjundioso prólogo contiene abundantes datos biográficos y estudia detenidamente casi todas las novelas de ABG, especialmente El loco Estero, e incluye unas «Fuentes consultables» (véase No. 199).

Hay apartado del prólogo y las «Fuentes...».

312. Fuenzalida Grandón, Alejandro: a Durante la Reconquista. Empresa Letras, 1933.

Es reproducción parcial de su trabajo «Algo acerca de Blest Gana...» (véase No. 268).

313. MattA, Guillermo: a Una escena social. Editorial Excélsior, s/f. [posiblemente 1922].

Es reproducción de su artículo en El Museo (véase No. 448).

314. RojAs, Manuel: a ABG: Sus mejores páginas. Editorial Ercilla, 1961, pp. 9-43.

Estudia principalmente La aritmética en el amor, Martín Rivas, El loco Estero y Durante la Reconquista. Enumera con entusiasmo los defectos de la novelística de ABG (fábula defectuosa, imitación, ninguna penetración psicológica, pésimo estilo, falta de sentido de la naturaleza, etc.) y con el mismo entusiasmo lo declara "padre de la novela chilena».

315. Román-Lagunas, Jorge: a Martín Rivas. Editorial Nascimento (1975), vol. I, pp. 7-22.

En el vol. II: «Fuentes de consulta sobre ABG» (véase No. 210).

316. _- a Martín Rivas. Barcelona, Editorial Vosgos (1977), pp. 5-13. 
317. - a El loco Estero. Barcelona, Editorial Vosgos (1977), pp. 1-10.

318. Scarpa, Roque Esteban: a Durante la Reconquista. Editorial Zig-Zag; 1946. También en la ed. de 1952.

319. Silva, Luis Ignacio: «Dos palabras del editor». En Una escena social. Editorial Excélsior, s/f. [posiblemente 1922].

320. Silva CAstro, Raúl: "Introducción» a El jefe de la familia. Editorial ZigZag (1956), pp. 7-12.

321. UMPH REY, G. M.: «Introduction» a Martín Rivas. Boston, Heath and Co. (1926), pp. IX-XV.

322. ZAmudio, José: «Introducción» a Costumbres y viajes (véase No. 194).

V. HISTORIAS DE LA LITERATURA, PANORAMAS, DICCIONARIOS, ETC.

323. Alegría, Fernando: Breve historia de la novela hispanoamericana. México, Ediciones De Andrea (1959), pp. 54-58. 3. ed. (Historia de la novela hispanoamericana), 1966.

Se refiere especialmente a Martín Rivas y Durante la Reconquista, señalándolas como «una de las historias más bellas del Romanticismo hispanoamericano» y «contribución maestra a la tradición del realismo romántico», respectivamente.

324. Amunátegui Solar, Domingo: Bosquejo histórico de la literatura chilena. Véase No. 248.

325. - L Las letras chilenas.

Véase No. 249.

326. Anderson-Imbert, Enrique: Historia de la literatura hispanoamericana. México, Fondo de Cultura Económica, 3. ${ }^{a}$ ed. (1961), vol. I, pp. 261-263.

327. Barbagelata, Hugo: La novela y el cuento en Hispanoamérica. Montevideo, Talleres Gráficos de Enrique Míguez y Cía. (1947), pp. 13-17.

Refiriéndose a $E l$ ideal de un calavera, estampa juicios tan absurdos como éste: «No se nos presenta personaje alguno que nos seduzca completamente por sus virtudes», y continúa con un chiste: «En este libro, como en los otros, todo ha de ser amor, amor del sexo.»

Las páginas dedicadas a $A B G$ no valen nada.

328. Bellini, Giuseppe, y Gallo, Ugo: Storia della letteratura ispanoamericana.

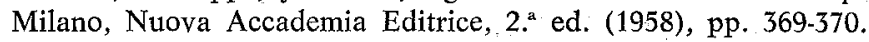

«... scrisse una serie di romanzi nei quali, sull' esemplo della Comedie Humaine, volle rappresentare il drama umano della sua nazione, el Cile.»

329. Carrasco, Aliro: Letras hispanoamericanas, desde la época colonial hasta nuestros dias. Imprenta Chile (1919), pp. 311-313.

Las páginas dedicadas a ABG están plagadas de errores. 
330. Castagnaro, R. Anthony: The Early Spanish American Novel. New York, Las Américas Publishing Co., 1971.

El capítulo dedicado a ABG ("The First Master of Realism», pp. 173182) es una atinada visión de conjunto.

331. Cento, M. I.: La novela hispanoamericana. Editorial Nascimento (1934), pp. 11 y 32.

A pesar de tratarse de un librito de 60 páginas, no dedica a ABG más de un par de referencias insignificantes.

332. Codina, Iverna: América en la novela. Buenos Aires, Ediciones Cruz del Sur (1964), p. 140.

Se refiere al valor de Durante la Reconquista y Los trasplantados como documentos históricos.

333. Conster, Alfred: The Literary History of Spanish America. New York, McMillan Co., 1916. 2. ${ }^{a}$ ed. (1928). Trad. como Historia literaria de la América española. Madrid, Editorial Hernando (1929), pp. 264-269.

334. Darreux, Max: Littérature Hispano-Américaine. Paris, Éditions Kra (1930), pp. 191-192.

Silva Castro anotó muchos de los errores de esta obra en su artículo «El panorama de Max Daireux» (Atenea, No. 63, 1930). En cuanto a ABG, todo está equivocado. Transcribimos uno de los disparates más notables: «Au Chili, Rosario Orrego de Uribe fût la créatrice de roman, elle est anterieure a Blest Gana...» La obra de Rosario Orrego es de 1861, año en el que ABG llevaba publicadas nueve novelas.

335. DíAz Arrieta, Hernán (Alone): Historia personal de la literatura chilena. Editorial Zig-Zag, 1954. 2.a ed. (1962), pp. 179-185. Reprod. como prólogo a Martín Rivas (véase No. 309).

Juicio de conjunto similar al estampado en la conclusión de su obra Don $A B G$ (No. 220). Se refiere especialmente a Durante la Reconquista.

336. Díez-Echarri, E., y Roca Franouesa, José: Historia de la literatura española e hispanoamericana. Madrid, Editorial Aguilar (1960), pp. 1132-1133 y 1147.

"Con él nace en América el relato realista y gracias a él pasa de simple cuadro de costumbres al rango de auténtica novela.» Se refieren principalmente a Martín Rivas, Los trasplantados y Durante la Reconquista.

337. Dussuel, Francisco: Literatura chilena (Del siglo XVI al XIX). Ediciones Paulinas (1959), vol. I, pp. 195-221.

Divide la obra de ABG en dos periodos, el primero hasta 1964. Preferimos la división en tres, porque se ajusta más a un criterio intrínseco que cronológico. No se puede incluir las endebles novelas iniciales junto a Martín Rivas: hay un mundo de diferencia.

338. EnglekiRK, John; LeonaRd, Irvin, y ReID, John: An Outline History of Spanish American Literature. New York, Appleton-Century-Crofts, 3. ${ }^{a}$ ed. (1965), pp. 91-92. 
339. Flores, Angel: Historia y antología del cuento y la novela en Hispanoamérica. New York, Las Américas Publishing Co. (1959), pp. 61-62.

340. Franco, Jean: Spanish American Literature Since Independence. London, Ernest Benn (1973), pp. 76-79. Trad. como Historia de la literatura hispanoamericana a partir de la Independencia. Barcelona, Editorial Ariel (1975), pp. 127-130.

341. Gorć, Cedomil: Historia de la novela hispanoamericana. Valparaíso, Ediciones Universitarias de Valparaíso (1972), pp. 89-93.

Señala su conciencia de «claro nacionalismo literario», expuesto en «De los trabajos literarios en Chile» y «Literatura chilena. Algunas consideraciones sobre ella», y llevado a cabo en su obra novelística como «ciclo de la historia del país».

342. Grossman, Rudolf: Geschichte und Probleme der Lateinamerikanischen Literatur. München, Max Hueber Verlag, 1969. Trad. como Historia y problemas de la literatura latinoamericana. Madrid, Ediciones de la Revista de Occidente (1972), pp. 348-349.

Divide la obra de ABG en dos períodos: 1853-1864 («que está bajo la égida de Balzac») y 1897-1913 («presidida por el signo de Flaubert»). Observa en Durante la Reconquista «una delectación en lo humilde y lo excitante, similar a la que se advierte, por ejemplo, en Salambó, de Flaubert».

343. Hamilton, Carlos: Historia de la literatura hispanoamericana. Primera parte. Colonia y siglo XIX. New York, Las Américas Publishing Co. (1960), pp. 150-152.

344. Hunneus Gana, Jorge: Cuadro histórico de la producción intelectual de Chile. Biblioteca de escritores de Chile, t. I (1910), pp. 733-739.

Interesante relación con W. Scott y Benito Pérez Galdós.

345. Latorre, Mariano: La literatura de Chile. Buenos Aires, Ediciones de la Universidad de Buenos Aires (1941), pp. 63-68.

En el capítulo III ( La novela santiaguina») estudia a ABG, Daniel Barros Grez y Moisés Vargas. Ve en las novelas del primero una «interpretación psicológica y objetiva de Santiago, desde la Independencia hasta los años que corren del siglo $\mathrm{xx}$ ».

346. LAzo, Raimundo: Historia de la literatura hispanoamericana. La Habana, Instituto del Libro (1969), t. II, pp. 159-160.

Como juicio de conjunto señala que su obra «es novela de un siglo y de un país» y que «en el transcurrir del siglo $\mathrm{xx}$, pasada su gran popularidad con su época, su valor es histórico». Por lo que se refiere a la «popularidad» de novelas como Martín Rivas, El loco Estero o Durante la Reconquista, pongamos sólo un ejemplo: Martín Rivas tuvo cinco ediciones en el siglo xIx y ya lleva treinta y dos en el presente siglo.

347. Livacic, Ernesto, y RoA, Alejo: Literatura chilena. Editorial salesiana de textos escolares (1955), pp. 36-39. 
348. Leguizamón, Julio: Historia de la literatura hispanoamericana. Buenos Aires, Editoriales Reunidas, S. A. (1945), t. II, pp. 104-107.

Lo clasifica como «romántico realista» y destaca el propósito cíclico de su obra.

349. Mengod, Vicente: Historia de la literatura chilena. Editorial Zig-Zag (1967), pp. 66-68.

350. Merino Reyes, Luis: Panorama de la literatura chilena. Washington, Unión Panamericana (1959), pp. 83-93.

Estudio principalmente biográfico.

351. Montes, Hugo, y OrLand, Julio: Historia de la literatura chilena. Editorial Zig-Zag (1974), pp. 113-119.

De esta obra hay ediciones anteriores y posteriores a la que citamos.

352. RoJAs, Manuel: Manual de literatura chilena. México, Ediciones de la Universidad Nacional Autónoma (1964), pp. 45, 49-54. [2. ed.]: Historia breve de la literatura chilena. Editorial Zig-Zag, 1965.

Distingue entre novelas «de contrapunto» (Martín Rivas, Durante la Reconquista) y hovelas «poemáticas» (El loco Estero).

353. SánchEz, Luis Alberto: Historia de la literatura americana (Desde los orígenes hasta 1936). Ediciones Ercilla (1937), pp. 341-342. [2. ${ }^{\mathrm{a}}$ ed.]: Nueva historia de la literatura americana. Buenos Aires, Editorial Américalee (1944), pp. 229-231.

354. - Proceso y contenido de la novela hispanoamericana. Madrid, Editorial Gredos (1953), pp. 51, 57, 249, 270, 378-379. 2. ${ }^{a}$ ed., 1968.

355. SAZ, Agustín del: Resumen de historia de la novela hispanoamericana. Barcelona, Editorial Seix-Barral, 1949. 2. ed., Editorial Atlántida (1953), pp. 99, 132, 138, 163-164.

356. SCARPA, Roque Esteban: Lecturas chilenas. Editorial Zig-Zag, 1956.

De esta obra hay ediciones en 1951 y 1963.

357. Silva Castro, Raúl: Creadores chilenos de personajes novelescos, Panorama de la novela chilena, Historia critica de la novela chilena y Panorama literario de Chile. Véase No. 293.

358. — : Diccionario de literatura latinoamericana. Chile. Washington, Unión Panamericana (1958), pp. 29-32.

Aunque Silva Castro es coautor de este diccionario, las páginas dedicadas a $A B G$ son enteramente suyas.

359. Solar, Claudio: «Diccionario de autores de la literatura chilena». Revista En viaje, No. 244, 1969.

360. SuÁrez-Murias, Marguerite: La novela romántica en Hispanoamérica. New York, Hispanic Institute in the U.S. (1963), pp. 112-113.

361. Szulewrcz, Efraín: Diccionario de literatura chilena. Selecciones Lautaro (1977), pp. 79-80.

362. TorRes-Rioseco, Arturo: La novela en la América hispánica. Berkeley (Cali- 
fornia), University of California Publications in Modern Philology, vol. 21, No. 2, pp. 159-256.

ABG en pp. 197-198: es reproducción de su artículo «La novela en América» (Revista Atenea, No. 141, marzo de 1937, pp. 323-325). Destaca su nacionalismo literario, lo llama «el novelista chileno por antonomasia», aunque reconoce su «estilo desaliñado y su falta de penetración en el alma humana».

363. - L La gran literatura iberoamericana. Buenos Aires, Emecé editores (1945), pp. 207-209. 3." ed. (Nueva historia de la gran literatura iberoamericana), 1960, pp. 175-176. Trad. como The Epic of Latin American Literature. New York, Oxford University Press (1946), pp. 170-173.

Se refiere principalmente a Martín Rivas y Durante la Reconquista.

364. - B Breve historia de la literatura chilena. México, Ediciones De Andrea (1956), pp. 60-62.

365. Uslar PIETri, Arturo: Breve historia de la novela hispanoamericana. Caracas, Ediciones Edime, s/f. [Introducción fechada en 1954], pp. 71-72.

Lo destaca principalmente como escritor costumbrista que «rara vez llega a provocar una emoción».

366. Zamudio, José: La novela histórica en Chile. Ediciones Flor Nacional (1949), pp. 63-67.

367. ZuM FELDE, Alberto: Indice crítico de la literatura hispanoamericana. La narrativa. México, Editorial Guarania, 1959.

368. - La narrativa en Hispanoamérica. Madrid, Editorial Aguilar (1964), pp. 64-65, 142-144.

\section{RESEÑAS, NOTAS, REFERENCIAS}

369. ANDERSON IMBERT, Enrique: «Notas sobre la novela histórica en el siglo XIX». En La novela hispanoamericana (Memoria al 5. Congreso del Instituto Internacional de Literatura Hispanoamericana), Albuquerque (Nuevo México), 1952, pp. 21-24. Reprod. en Estudios sobre escritores de América. Buenos Aires, Editorial Raigal (1954), pp. 24-26, y en Juan Loveluck: La novela hispanoamericana, 1963 (3. ${ }^{\text {ed., }}$ 1969).

«Quizá las dos mejores novelas históricas del período realista fueron el Enriquillo del dominicano Manuel de Jesús Galván y Durante la Reconquista del chileno ABG.» Además, señala la Historia general de Chile de Barros Arana como la principal fuente de la novela.

370. Anónimo: «Martín Rivas translated by C. Whitman, 1918». Review of reviews, vol. 57 (1918), p. 557.

371. - - «Martin Rivas translated by C. Whitman, 1918». Booklist, t. 15 (1918), p. 107.

372. —-: «Martin Rivas translated by Mrs. C. Whitman, 1918». New York Times, May 5, 1918.

373. — : «Llega a Valparaíso una hija de Blest Gana». El Mercurio [¿?], 1921. 
374. - : «Blest Gana en su vida íntima. Los últimos años del gran novelista chileno. Conversando con la señora Blanca Blest Gana de Nariño». La Nación [i?], 1921.

375. - - «Epoca que se va». La Nación, 4-IV-1954.

376. - «Alberto Blest Gana». La Nación, 9-V-1954.

377. — : «¿Cuándo fue?». La Nación, 16-V-1954.

378. ——: (Firmado «Sir Arthur»): «Vuelve un trasplantado». La Nación, 14-VII1955.

379. — : «Sobre repatriación de los restos de Blest Gana». El Mercurio, 27-VII1955.

380. - : (Firmado «L»): «El jefe de la familia». El Mercurio, 18-IX-1956.

381. - : (Firmado "C. H. J.»): "El jefe de [sic] familia. Comedia en tres actos de Alberto Blest Gana». El Diario Ilustrado, 19-V-1959.

382. — : "Durante la Reconquista». Revista Flash, No. 259, 16-VII-1958.

383. - (Firmado «Pluto»): "Martín Rivas a gogó». La Tercera de la Hora, 20-IV-1970.

384. - : «Diccionario de la cultura chilena. El loco Estero». La Estrella (Valparaíso), 11-XII-1971

385. - : «Alberto Blest Gana». La Unión (Valparaíso), 25-IV-1971.

386. Arteaga Alemparte, Domingo: «Ecos de la Semana». La Semana, No. 10 (23-VII-1859), pp. 158-160.

387. - - :Don Alberto Blest Gana». En Los Constituyentes de 1870. (Por Justo y Domingo Arteaga Alemparte), Biblioteca de escritores de Chile (1910), pp. 434-438.

Es una breve semblanza biográfica.

388. Balmaceda Valdés, Eduardo: De mi tierra y de Francia. Editorial Ercilla, 1932.

Referencias en la primera parte, capítulo VII.

389. Balmaceda Toro, Pedro: Estudios y ensayos literarios. Imprenta Cervantes (1889), pp. 233-23.9,

"Anecdotes and the character of the man» (Leavitt: Chilean Literature...).

390. Barceló Lira, Luis: La Segunda Conferencia Internacional Panamericana. México, Imprenta de Estampillas (Palacio Nacional); 1902.

Datos sobre las últimas tareas diplomáticas de ABG.

391. Barría Navarro, Nelson: "Martín Rivas, protagonista de la sociedad actual», ¿El Siglo?, 21-V-1972.

392. Barros Arana, Diego (Firmado «D. B. A.): «Revista bibliográfica». Revista chilena, t. II, 1875.

393. Bello, Emilio: Memoria presentada al Depto. de Relaciones Exteriores, 1902.

Se refiere a la Conferencia de México (1901), en la que ABG participó.

394. Berenberg, D. F.: «Martín Rivas translated by C. Whitman». New York Call, 18-V-1918. 
395. Blanco, Guillermo: «¿Por qué vive Martín Rivas?». Finis Terrae (Universidad Católica de Chile), No. 36 (1962), pp. 77-80.

Señala que la vigencia de la obra se debe a la creación de un arquetipo: el del provinciano en la capital.

396. - - «Vigencia de Blest Gana». El Mercurio, 27-XII-1970.

Desarrollan el mismo tema Leoncio Guerrero y Martín Cerda.

397. BRus HWood, John: «Alberto Blest Gana: Gladys Fairfield». Books Abroad, t. 25 (1951), pp. 376.

398. Cerda, Martín: «Vigencia de Alberto Blest Gana».

Véase No. 396.

399. Cid, Enrique: «Montaje de Martín Rivas por Teatro de Ensayo batió récord presupuestario municipal: agotó entradas en 6 funciones». Ercilla, 18-V-1954.

400. Correa Pastene, Misael: «Don Alberto Blest Gana». Revista Sucesos, 9-XII1920.

401. - :Leonor Encina, protagonista de la novela Martín Rivas, de Alberto Blest Gana». Revista Sucesos, 13-VIII-1925.

402. - : «Costumbres y viajes (Páginas olvidadas), por Alberto Blest Gana». El Diario Ilustrado, 29-VI-1947.

Se refiere a la recopilación de José Zamudio (No. 194).

403. Cortés, José Domingo: Diccionario biográfico americano. París, Editorial Lahure, 1875. 2. ${ }^{a}$ ed. (1876), p. 75.

Equivoca todo. Desde la fecha de nacimiento hasta algunos títulos de novelas.

404. Del Campo, Santiago: «Martín Rivas en teatro». El Mercurio, 2-V-1954.

405. DE LUIGI, Juan (Firmado «The Ripper»): «Los trasplantados, por Alberto Blest Gana». La Hora, 10-I-1937.

406. DÉlANo, Enrique: «El padre de la novela chilena». Ultima Hora, 28-VIII1968.

407. DeL Solar, Hernán: «Blest Gana: Obras selectas». El Mercurio, 26-VII1970.

Se refiere a la edición de Buenos Aires, en 3 vols. (No. 197).

408. DíAz Arrieta, Hernán (Alone): [«Sobre Blest Gana»]. Gaceta literaria (Madrid), 15-XI-1930. Reprod. en Panorama de la literatura chilena durante el siglo XX. Editorial Nascimento (1931), pp. 29-30.

409. - «E1 Portales de Blest Gana». La Nación, 6-VI-1937.

410. - : - Cincuentenario de la muerte de don Alberto Blest Gana». El Mercurio, 19-VII-1970.

411. - : «uincuagésimo aniversario de Blest Gana». El Mercurio, 27-VI-1971.

412. DíAz GARcÉs, Joaquín: [«Sobre El ideal de un calavera»]. En Luis Ignacio Silva: La novela en Chile, pp. 71-73.

413. —- «Blest Gana». El Diario Ilustrado, 11-XI-1920.

414. DíAz, Miguel Angel: «Don Alberto Blest Gana». La Nación, 23-VIII-1956.

415. __- " «Alberto Blest Gana, novelista del pasado». La Nación, 21-I-1962. 
416. Donoso, Armando (Firmado «A. D.»): «Recuerdos de una hermana del novelista. Conversando con la señorita Luz Blest Gana». El Mercurio; 11-XI1920.

417. Donoso, Ricardo: «Un amigo de Blest Gana: José Antonio Donoso». En Homenaje a Domingo Amunátegui Solar, t. II, pp. 177-200.

Hay apartado.

418. Durand, Luis: «Durante la Reconquista». El Mercurio [¿?], 1930.

419. Echeverría DE LARraín, Inés (Firmado «Rainbow»): «El hogar de Blest Gana: páginas de un diario íntimo». La Nación, 17-XI-1920.

420. Edwards, Agustín: My Native Land. Londres, Ernest Benn (1928), pp. 360362. Trad. como Mi tierra, Valparaíso, 1928.

421. Figueroa, Pedro Pablo: Prosistas y poetas de América moderna. Bogotá, Casa editorial de J. J. Pérez (1891), pp. 263-269.

422. —-: Antología chilena. Prosistas y poetas contemporáneos. Imprenta La Ilustración (1908), pp. 363-369.

423. - Diccionario histórico, biográfico y bibliográfico de Chile. Editorial Balcells (1928), pp. 226-229.

424. FuENZALIDA GRANDÓN, Alejandro: Valor histórico de la novela social contemporánea (Memoria premiada en el Certamen Universitario de 1885). Imprenta Nacional (1889), pp. 36-40.

«After a brief discussion of the traits of Chilean novelists beginning with Barros Grez and Blest Gana...» (Leavitt: Chilean Literature...).

425. Gorć, Cedomil: «Brevísima relación de la historia de la novela hispanoamericana». En Cedomil Goić y otros: La novela hispanoamericana. Descubrimiento e invención de América. Ediciones universitarias en Valparaíso, 1973.

En pp. 25-26 enfatiza el estudio social en la novela de ABG y su americanismo (pintoresquismo y color local).

426. GoldBerg, Isaac: «Alberto Blest Gana: Martin Rivas, translated by C. Whitman», Boston Evening Transcript, 20-IV-1918.

427. González Salinas, Edmundo: «Alberto Blest Gana, diplomático y escritor». La Nación, 1-VII-1962.

428. Guerrero, Leoncio: «Vigencia de Alberto Blest Gana».

Véase No. 396.

429. HERnÁNDEZ, Roberto: «Entrevista sobre recuerdos literarios». La Unión (Valparaíso), 1-VI-1919.

430. (Firmado «R. H.»): «Don Alberto Blest Gana: algunos rasgos de su hermosa labor literaria». La Unión (Valparaíso), 12-XI-1920.

431. - (Firmado «R. H.»): «El tronco común de un grupo selecto de escritores chilenos». La Unión (Valparaíso), 21-XI-1920.

432. (Firmado «R. H.»): «Con doña Blanca Blest Gana de Nariño». La Unión (Valparaíso), 7-III-1921.

433. - (Firmado «R. H.»): "Durante la Reconquista, por Alberto Blest Gana». La Únión (Valparaíso), 17-XI-1927.

434. Henríouez UREÑA, Max: «Influencias francesas en la novela de la América española». En La cultura y la literatura iberoamericana (Memoria del séptimo Congreso del Instituto Internacional de Literatura Iberoamericana, Berkeley, 
Calif̣ornia, 1955). Edit. en México, Ediciones De Andrea, 1957. Reprod. en Juan Loveluck: La novela hispanoamericana, pp. 249-270.

Se refiere a la influencia de Balzac en Blest Gana y agrega que «en tesis general, puede decirse que todo novelista hispanoamericano de la segunda mitad del siglo xIX fue tributario de Balzac, si bien algunos siguieron, al mismo tiempo, las huellas de los más afamados autores españoles contemporáneos, como Valera, Pereda y Pérez Galdós».

435. Henríouez Ureña, Pedro: Las corrientes literarias en la América hispánica. México, Fondo de Cultura Económica (1949), pp. 151-152 y 254.

«La novela realista, que había comenzado en la América hispana con BG y Almeida...» Y en otro párrafo: «... como había ocurrido con el romanticismo en poesía, el realismo moderno en la novela hizo su aparición en la América española antes que en España.»

436. Holmes, Henry Alfred: Spanish-America in Song and Story. New York, Henry Holt and Co., 1932.

Lo llama el «W. Scott of the Chilean novel» y lo declara autor de Los implantados [sic].

437. Huerta, Eleazar: «Alberto Blest Gana: El loco Estero». Las Ultimas Noticias, 23-VIII-1947.

438. - «Alberto Blest Gana: El pago de las deudas». Las Ultimas Noticias, 3-IX-1949.

439. Hunneus Gana, Roberto: «Resurrección». Revista chilena, t. 4 (1900), pp. 130140, 162-169, 197.204, 228-233.

Dato tomado de David W. Foster: Chilean literature. A king... (No. 202).

440. - :- "Don Carlos Morla Vicuña». Revista de Chile (1901), pp. 193-224.

Morla Vicuña trabajó muchos años junto a ABG en Europa.

441. Jones, Willis Knap: «Alberto Blest Gana: El jefe de la familia y otras páginas». Books Abroad, t. 32 (1958), pp. 175-176.

442. Labrador RuIz, Enrique: "Vigencia de Alberto Blest Gana». Repertorio americano, t. 40, No. 18, 13-X-1943.

Muchos errores para un artículo tan breve. Por ejemplo, dice que en 1860 aparece su primer libro.

443. LaRraín Zañartu, José Joaquín: Los políticos de 1870 ante el tribunal de La Opinión. Valparaíso, Imprenta de El Mercurio (1879), p. 149.

444. Latcham, Ricardo: «Costumbres y viajes (Páginas olvidadas). Por Alberto Blest Gana». La Nación, 20-VII-1947.

Se refiere a la recopilación de José Zamudio.

445. - "Five Years of Chilean Literature». Américas (Washington), vol. 6, No. 12 (diciembre de 1964), p. 38.

Se refiere al éxito de la puesta en escena de Martín Rivas por el Teatro de Ensayo de la Universidad Católica de Chile, en Santiago. (Versión de Santiago del Campo.) 
446. LoVeluck, Juan: La novela hispanoamericana. Editorial Universitaria, 1963. 3. ${ }^{\mathrm{a}}$ ed. (actualizada), 1969.

Los estudios atingentes a $A B G$ incluidos por Loveluck se consignan por el apellido de sus autores.

447. Mackenna Subercaseaux, Alberto: [«Sobre Los trasplantados»]. En Luis Ignacio Silva: La novela en Chile, pp. 83-102.

448. MatTA, Guillermo: «Una escena social, por don Alberto Blest Gana». El Museo, No. 21 (1853), pp. 326-328.

Reprod. como prólogo a Una escena social (véase No. 2).

449. Melfi, Domingo: «Novelists and Story Writers of Chile. A Survey of the Development of a Literary Form that Reveals Distinctive Traits». Chile (New York), mayo de 1930, p. 220.

450. - "Martin Rivas Marks the Rise of the Middle Class in Chilean Literature». Chile (New York), octubre de 1930, p. 125.

451. - : «Max Henriquez Ureña y Blest Gana». El Mercurio, 9-XI-1930.

452. Merino Reyes, Luis: «Blest Gana a 50 años de su muerte». El Siglo, 20-XII1970.

453. Morgado, Benjamín: «Autores teatrales del siglo xIX». Revista de Occidente, No. 221 (octubre de 1970), p. 36.

454. Morla LYNCH, Carlos: «Recordando». La Nación, 11-XI-1920.

455. Peña Munizaga, Nicolás: Teatro dramático nacional. Biblioteca de escritores de Chile, t. IX, 1912.

ABG en la p. XVIX de la introducción. Es una nota sobre el argumento de $E l$ jefe de la familia.

456. Pereira Salas, Eugenio: prólogo a José Zapiola: Recuerdos de treinta años. Editorial Zig-Zag (1945), 8. ed. «definitiva», p. 22.

457. Ramírez Jones, Julia: Los precursores de la novela en Chile. Memoria de Grado, Universidad de Chile. Publicada por Imprenta Cervantes, 1923.

«Trata de varios autores del siglo pasado, en forma superficialísima y poco documentada» (Raúl Silva Castro: Fuentes para el estudio de la literatura chilena). El aserto es enteramente aplicable al caso de ABG.

458. Rodríguez Mendoza, Emilio: Remansos del tiempo. Madrid, Compañía Iberoamericana de Publicaciones [1929].

Dato de Alfonso Escudero: «Fuentes consultables» (véase No. 199).

459. _- «Unamunizando». La Habana, 10-I-1937. Reprod. en La flecha en el arco. Editorial Ercilla (1940), pp. 147-151.

Se refiere a la opinión adversa de Unamuno sobre las novelas de ABG.

460. Rodríguez Santiago, José: «Hacia una comprensión del roto a través de algunos autores nacionales». Memoria de grado, Universidad de Chile, 1959.

461. SABELla, Andrés: «Crónica de muchos filos». El Mercurio (Antofagasta), 9-VIII-1968.

462. —-: «Los Blest Gana y la 'U'». El Mercurio (Antofagasta), 19-XI-1970.

463. — : «Los sábados de Andrés Sabella». La Estrella del Norte (Antofagasta), 5-X-1968. 
464. SANTA María, Ignacio (Firmado «I. S. M.»): «Don Domingo Santa María y don Alberto Blest Gana». Revista chilena, No. 37 (diciembre de 1920). pp. 310-312.

465. SepúlvedA, Germán: «El jefe de la familia y otras páginas, de Alberto Blest Gana». La Nación, 6-I-1957.

Se refiere a la recopilación de Raúl Silva Castro (No. 195).

466. Silva Castro, Raúl: Cartas chilenas. Publicaciones de la Academia Chilena de la Historia, 1954.

Sabemos que contiene cartas de $\mathrm{ABG}$, pero no hemos logrado consultar este trabajo.

467. —- «Blest Gana en el ambiente de su época». El Mercurio, 28-VII-1968.

Se refiere a la obra de Hernán Poblete Varas Genio y figura de $A B G$ (No. 223).

468. Silva Vildósola, Carlos: «Alberto Blest Gana». El Mercurio, 19-VI-1901.

469. - Retratos y recuerdos. Editorial Zig-Zag (1936), pp. 71-83.

470. Silva Yoacham, Víctor (Firmado «V. S. Y.»): «Los trasplantados, por Alberto Blest Gana». El Mercurio, 6-XII-1936.

471. SolAR, Claudio: "La aritmética en el amor». La Estrella (Valparaíso), 27-III1968.

472. —_: «Durante la Reconquista». La Estrella (Valparaíso), 5-VII-1968.

473. SOlAR Correa, Eduardo: Escritores de Chile, t. II, Imprenta Universitaria (1932), pp. 82-83.

474. Subercaseaux, Ramón: Memorias de 50 años, 1908.

Referencias anecdóticas.

475. TAGLE Moreno, Enrique (Firmado «Víctor Noir»): «Blest Gana». La Nación, 11-XI-1920.

476. Urbina, Cornelio: «Itinerario del roto a través de la literatura chilena». Boletín del Instituto Nacional, No. 6, noviembre de 1941.

477. VAÏSSE, Emilio (Omer Emeth): «Un drama histórico nacional: Durante la Reconquista, por Carlos Mondaca y Max Jara». El Mercurio, 5-III-1911.

Se refiere a la adaptación escénica de Durante la Reconquista por los autores citados.

478. VAlenZuela, Renato: «El jefe de la familia». La Nación, 24-V-1959.

479. Vargas Fontecilla, Francisco: «Producciones literarias». Revista Católica, No. 330, 21-X-1853. Reprod. en Raúl Silva Castro: $A B G$ (edición de 1941); y reprod. parcialmente en Domingo Amunátegui Solar: Bosquejo histórico de la literatura chilena.

Véanse Nos. 224 y 249 , respectivamente.

480. VicuÑa Mackenna, Carlos: «Discurso» (en representación de la Sociedad Chilena de Historia y Geografía en el Ateneo de Santiago). Revista chilena de Historia y Geografía, No. 43 (1921), pp. 5-11.

481. Vicuña Subercaseaux, Benjamín: La ciudad de las ciudades (correspondencia de París), 1905, pp. 518-526. 
482. - G Gobernantes y literatos. Imprenta y Litografía Universo (1907), pp. 197205.

"Gives a brief appreciation on his works and some facts about his life» (Leavitt: Chilean Literature...).

483. _ - Memoria sobre la producción intelectual de Chile. Sociedad Imprenta y Litografía Universo (1909), p. 88.

484. Zamudio, José: «Novela histórica y romanticismo en Chile». Revista Atenea, No. 389 (julio-septiembre de 1960), pp. 255-259. 


\section{INDICE ONOMASTICO}

AcEvedo DíAz, Eduardo: 235.

Aguayo Dolmetsch, Lidia: 235.

ALDAO, Martín: 273.

AlEGRÍA, Fernando: 323.

Alonso, Amado: 257.

Altamirano, Ignacio: 284.

AmunÁteguı, Miguel Luis: 214, 247, 295.

AmunÁtegui Solar, Domingo: 248, 249, 324, 325, 417, 479.

ANDERSON, Robert R.: 289.

ANDERSON IMBERT, Enrique: 326, 369.

Araya, Guillermo: 250.

Arteaga Alemparte, Domingo: 386, 387.

ArteagA Alemparte, Justo: 214, 251, 287.

Astorquiza, Eliodoro: 252.

Balmaceda Toro, Pedro: 389.

Balmaceda Valdés, Eduardo: 388.

BALZAC, H. de: $186,220,229,252,266$, 272, 273, 284, 328, 340, 434.

Barbagelata, Hugo: 327 .

BARCEló LiRA, Luis: 390.

BARRET, Ivonne: 225.

Barría Navarro, Nelson: 391.

Barros Rrana, Diego: 214, 253, 254, 303, 369, 391.

Barros Grez, Daniel: 255, 345, 424.

BAZÁN, Armando: 107, 121，139，304, 305.

Beremberg, D. F.: 394.

BellinI, Giuseppe: 328.

Bello, Emilio: 393.
Bilbao, Manuel: 333

BILlONE, Vicente Atilio: 256.

BLANCO, Guillermo: 395, 396.

Blest Gana, Luz: 416.

Blest GaNA DE NARIÑo, Blanca: 374, 432.

Bull FigueroA, Ernestina: 326.

Calderón, Alfonso: 272.

CAMuratt, Mireya: 257.

Carrasco, Aliro: 329.

Castagnaro, Anthony: 330.

Castillo, Homero: 8, 37, 62, 98, 119 , 154, 213, 215.

Cento, M. I.: 331.

Cerda, Martín: 396, 398.

CID, Enrique: 399.

Clerc, Teresa: 258.

CODINA, Iverna: 332.

Coester, Alfred: 333.

CONCHA, Jaime: 259, 306.

Correa Pastene, Misael: 400, 401, 402.

Cortés, José Domingo: 403.

Crowley, Cornelius: 260.

Cruz, Pedro Nolasco: 261.

Cuadra, Fernando: 262.

CuÉllar, José Tomás de: 273.

Daireux, Max: 334.

DÉlANo, Enrique: 406.

DEL CAMPO, Santiago: $404,445$.

Del Solar, Alberto: 273.

DE Luigi, Juan: 405.

DíAz, Miguel Angel: 414, 415.

Díaz ARrieta, Hernán (Alone): 41, 90 , $94,95,108,113,114,127,135,142$, 
$146,148,149,150,197,198,220,224$, 233, 248, 308, 309, 310, 335, 337, 407, 408, 409, 410, 411.

DíAz Garcés, Joaquín: 314, 412, 413.

DICKENS, Charles: 273.

DíEz Echarri, E.: 336.

Donoso, Armando: 416.

Donoso, José Antonio: 417.

Donoso, Ricardo, 417.

DunN, K. L.: 229.

Durand, Luis: 258, 263, 267, 418.

Dussuel, Francisco: 337.

EcheVERRía de LaRRAín, Inés: 419.

EDWARDS, Agustín: 420.

EDWARDS, Alberto: 264.

EDWARDS BELLO, Joaquín: 273.

ENGLEKIRK, John: 338.

Escudero, Alfonso M.: 140, 141, 199, $311,458$.

FAH RENKAMP, Billie Mae: 265.

Figueroa, Pedro Pablo: 421, 422, 423.

FlauberT, Gustave: 342.

Flores, Angel: 200, 201, 339.

Foster, David W.: 202, 439.

Franco, Jean: 340 .

FRAYSE, Maurice: 266, 267.

Fuentes Rodríguez, María Teresa: 237.

Fuenzalida Grandón, Alejandro: 120, $268,312,424$.

GaLlo, Ugo: 328.

Galván, Manuel de Jesús: 369.

Gelfant, Blanche H.: 282.

GoIć, Cedomil: 203, 204, 255, 269, 275, $341,425$.

GolDBERG, Isaac: 426.

GoNZÁleZ GuZMÁn, Adriana: 238.

GonZÁlez Salinas, Edmundo: 427.

Grez, Vicente: 280.

GrISMER, Mildred: 205.

GRISMER, Raymond: 205.

GrossMANN, Rudolf: 342.

Guerrero, Leoncio: 270, 396, 428.

Hamilton, Carlos: 343.

Heinzman, M. B.: 230.

Henríouez Ureña, Max: 434, 451.

Henríquez Ureña, Pedro: 435.

HERNÁNDEZ, Roberto: 429, 430, 431, 432, 433.

Holmes, Henry Alfred: 436.

Holton, James Stafford: 271.
Hubbard, Marie: 193.

HuERTA, Eleazar: 437, 438.

Hugo, Víctor: 250.

Hunneus Gana, Jorge: 344.

HunNeus GanA, Roberto: 221, 439, 440.

IsAACS, Jorge: 284.

JARA, Max: 477.

JoNEs, Willis Knapp: 441.

LABRADOR Ruiz, Enrique: 442.

LARRAÍn ZAÑARTU, José Joaquín: 443.

LASTARRIA, José Victorino: 184, 186, 214, 247, 275, 295.

Lastra, Pedro: 272.

LATC H AM, Ricardo: $272,273,444,445$.

LAtorre, Mariano: 267, 274, 345.

LAzo, Raimundo: 346.

LEAVIT, Sturgis: 184, 208, 221, 424, 483.

Leguizamón, Julio: 348.

LEONARD, Irving: 338.

LIVACIC, Ernesto: 347.

LOGAN, M. E.: 231.

LoveLuck, Juan: 369, 434, 446.

LOYOLA, Hernán: 275.

LuKÁcs, George: 257.

Mackenna Subercaseaux, Alberto: 214, 447.

MaluendA, Rafael: 267.

MatTa, Guillermo: 2, 313, 448.

MCKNIGT H, T. M.: 232.

Melfi, Domingo: 276, 277, 278, 449, $450,451$.

MENGOD, Vicente: 349.

Merino Reyes, Luis: 279, 350, 452.

Miller, Edmund D.: 222.

Miranda Lazcano, Rebeca: 280.

MONDACA, Carlos: 477.

Montaner Bello, Ricardo: 281.

Montes, Hugo: 351.

Morand, Carlos: 282.

Morgado, Benjamín: 453.

Morla Vicuña, Carlos: 440.

Neves, Eugenia: 239.

NúÑEz, Fresia: 240.

OrLANDI, Julio: 351.

ORREGO DE URIBE, Rosario: 334.

OrRego LuCo, Luis: 278, 280.

Ortiz Morales, Berta: 241.

Peña Munizaga, Nicolás: 455.

Pereda, José María: 434.

Pereira Salas, Eugenio: 456. 
Pérez, Margot: 242.

Pérez Galdós, Benito: 344, 434.

Phillips, Walter T.: 226, 283.

Poblete Varas, Hernán: 223, 299, 467.

PoOL, Alice M.: 284.

Promis, José: 185.

RAMírez Jones, Julia: 457.

RAYMOND, Ethel G.: 233.

REID, John: 338.

ReLA, Walter: 209.

Riquelme, Daniel: 287.

RoA, Alejo: 347.

Roca Franouesa, José: 336.

RODRÍGUEZ MENDOZA, Emilio: 285, 458, 459.

Rodríguez Santiago, José: 460.

RoJAs, Manuel: 196, 315, 352.

ROMÁN-LAGUNAS, Jorge: 96, 97, 151, 210, 211, 212, 315, 316, 317.

Rosaldo, Renato: 289.

ROSSEL, Milton: 286.

SABELla, Andrés: 461, 462, 463.

SALMON, Russel: 287, 288.

SALGAdo Vera, Rosa: 243.

SÁNCHEZ, Luis Alberto: 353, 354.

Santa María, Domingo: 464.

Santa María, Ignacio: 464.

SANTANDREU, Cora: 244.

SAZ, Agustín del: 355.

Scarpa, Roque Esteban: 122, 123, 318, 356.

Scotr, Sir Walter: 273, 344, 436.

Sc HADE, George D.: 289.

Schaible, Carlos: 68, 213.

SEPÚlveda, Germán: 465.

Seura, Carlos: 290.

Silva, Luis Ignacio: 2, 214, 247, 251, 253, 254, 319, 447.

Silva Castro, Raúl: 8, 37, 62, 98, 119, $154,159,185,195,213,215,216,217$, $220,223,224,251,291,292,293,294$, 295, 296, 297, 298, 299, 300, 301, 320,
$334,357,358,441,457,465,466,467$, 479.

Silva Vildósola, Carlos: 468, 469, 470.

SILVA YoACHAM, Víctor: 470.

Silvester Briso, Inés: 245.

Solar, Claudio: $359,471,472$.

Solar Correa, Eduardo: 473.

STEND H AL: 284.

SUÁREZ-MURIAS, Marguerite: 360 .

Subercaseaux, Ramón: 474.

SzMULEWICZ, Efraín: 361.

Tagle Moreno, Enrique: 475.

TOPETE, J. Manuel: 218.

TORRES-Rioseco, Arturo: 217, 362, 363, 364.

UMPHREY, G. W.: 71, 321.

Unamuno, Miguel de: 459.

UrbinA, Cornelio: 476.

URZÚA, Leonor: 187.

Uslar Pietri, Arturo: 365.

VaÏsse, Emilio (Omer Emeth): 300, 477.

VALENZUELA, Renato: 478.

VALENZUELA, Víctor M.: 219, 227.

VALERA, Juan: 434.

VALLEjo, José Joaquín (Jotabeche): 287.

VARGAS, Moisés: 280, 345.

VARGAS Fontecilla, Francisco: 479.

Verdugo de Navarro, Esperanza: 246.

Vicuña Mackenna, Benjamín: 186, 301.

Vicuña Macienna, Carlos: 480.

Vicuña Subercaseaux, Benjamín: 481, $482,483$.

Von Dem Bussche, Gastón: 302.

WHITEH OUSE, J. E.: 234.

W hitman, Mrs. Charles: 190, 192, 370, 371, 372, 394.

WILsoN, William: 228, 303.

WINTER, C.: 300.

ZAMudio, José: $194,322,366,402,444$, 484.

ZAPIOLA, José: 456.

Zum Felde, Alberto: 367, 368. 
